NBER WORKING PAPER SERIES

\title{
ENVIRONMENTAL POLICY AS SOCIAL POLICY? THE IMPACT OF CHILDHOOD LEAD EXPOSURE ON CRIME
}

\author{
Jessica Wolpaw Reyes \\ Working Paper 13097 \\ http://www.nber.org/papers/w13097

\begin{abstract}
NATIONAL BUREAU OF ECONOMIC RESEARCH
1050 Massachusetts Avenue

Cambridge, MA 02138
\end{abstract}

May 2007

I would especially like to thank Lawrence Katz for valuable advice, as well as David Cutler, Leemore Dafny, Amy Finkelstein, Claudia Goldin, Nora Gordon, Christopher Jencks, Walter Nicholson, Linda Reyes, René Reyes, Steven Rivkin, Geoffrey Woglom, Justin Wolfers, two anonymous referees, and many seminar participants. Numerous individuals at government agencies and petroleum industry companies generously provided data on lead in gasoline. Brent Mast, Bomy Hong, and John Indellicate II provided excellent research assistance. Any remaining errors are my own. This research was supported by grants from the National Science Foundation, the National Bureau of Economic Research, the National Institute on Aging, and the Harvard Multidisciplinary Program in Inequality and Social Policy. The views expressed herein are those of the author(s) and do not necessarily reflect the views of the National Bureau of Economic Research.

(C) 2007 by Jessica Wolpaw Reyes. All rights reserved. Short sections of text, not to exceed two paragraphs, may be quoted without explicit permission provided that full credit, including $@$ notice, is given to the source. 
Environmental Policy as Social Policy? The Impact of Childhood Lead Exposure on Crime Jessica Wolpaw Reyes

NBER Working Paper No. 13097

May 2007

JEL No. I18,K49,Q53,Q58

\begin{abstract}
$\underline{\text { ABSTRACT }}$
Childhood lead exposure can lead to psychological deficits that are strongly associated with aggressive and criminal behavior. In the late 1970s in the United States, lead was removed from gasoline under the Clean Air Act. Using the sharp state-specific reductions in lead exposure resulting from this removal, this article finds that the reduction in childhood lead exposure in the late 1970s and early 1980s is responsible for significant declines in violent crime in the 1990s, and may cause further declines into the future. The elasticity of violent crime with respect to lead is estimated to be approximately 0.8 .

Jessica Wolpaw Reyes

Department of Economics

Amherst College

Amherst, MA 01002

and NBER

jwreyes@amherst.edu
\end{abstract}




\section{Introduction}

In the 1990 s, after decades of relatively steady increase, crime rates in the United States began a sharp and surprising decline. Researchers have investigated many possible explanations for this decline. Most recently, Levitt [2004] argues that the decline in crime in the 1990s is primarily explained by increases in the number of police, the size of the prison population, the waning crack epidemic, and the legalization of abortion in the 1970s. This paper argues that the removal of lead from gasoline in the late 1970s under the Clean Air Act is an additional important factor in explaining the decline in crime in the 1990s. The main result of the paper is that changes in childhood lead exposure are responsible for a 56\% drop in violent crime in the 1990 s.

There are substantial reasons to expect that a person's lead exposure as a child could affect the likelihood that he might commit a crime as an adult. Childhood lead exposure increases the likelihood of behavioral and cognitive traits such as impulsivity, aggressivity, and low IQ that are strongly associated with criminal behavior. Under the 1970 Clean Air Act, lead was almost entirely removed from gasoline between 1975 and 1985. Children exposed to significant lead in the early 1970s may have been more likely to grow up to be impulsive or aggressive adults who committed crimes in the late 1980s and early 1990s. On the other hand, children born in the 1980s, who experienced drastically lower lead exposure after the phase-out of lead from gasoline, may have been much less likely to commit crimes when they became adults in the late 1990s and early 2000s. As each cohort approaches adulthood, the sharp declines in lead exposure that occurred between 1975 and 1985 would be revealed in their behavior as adults. By the year 2020, all adults in their 20s and 30s will have grown up without any direct exposure to gasoline lead in childhood, and their crime rates should be correspondingly lower.

This paper uses state-level observations to identify this connection between lead exposure 
and crime. I construct a panel of state-year observations by linking crime rates in a state in a given year to childhood lead exposure in that state 20 or 30 years earlier. I evaluate this link for all 51 states (including the District of Columbia) for crime in the years 1985 to 2002. The link between lead and crime is thus identified off of the variation of lead exposure and crime over time within each state. Lead exposure is measured both as lead in gasoline and lead in the air, and these lead exposure measures are tested against individual-level blood data on children's lead exposure. I test the robustness of the crime results in various ways, including robustness to sample restrictions, alternate specifications, and alternate methods of measuring childhood lead exposure. Overall, the sensitivity testing confirms the strength of the main results.

The elasticity of violent crime with respect to childhood lead exposure is estimated to be approximately 0.8 . This implies that, between 1992 and 2002, the phase-out of lead from gasoline was responsible for approximately a 56\% decline in violent crime. Results for murder are not robust if New York and the District of Columbia are included, but suggest a substantial elasticity as well. No significant effects are found for property crime. The effect of legalized abortion reported by Donohue and Levitt [2001] is largely unaffected, so that abortion accounts for a $29 \%$ decline in violent crime (elasticity 0.23 ), and similar declines in murder and property crime. Overall, the phase-out of lead and the legalization of abortion appear to have been responsible for significant reductions in violent crime rates.

This paper shows that childhood lead exposure can increase the likelihood of violent criminal behavior, and that this effect is large enough to significantly affect national crime trends. It provides a surprising explanation for rising and declining crime rates, and predicts continuing declines in the future. Lastly, this paper shows that environmental regulations such as the Clean Air Act can have large and unexpected societal benefits. 
The paper is organized as follows. Section II discusses lead, and Section III explains the association between childhood lead exposure and criminal behavior. Section IV discusses the measurement of lead exposure and introduces the data. Section V presents the empirical results, Section VI provides interpretation, and Section VII concludes.

\section{Lead}

Lead is an extremely useful metal but unfortunately has also proved to be a dangerous toxin. Lead exposure is particularly dangerous to young children because they absorb more lead from their environment and are at a critical and sensitive stage of their neurobehavioral development. ${ }^{1}$ It was not until after 1950 that it was widely accepted that the neurological effects of lead persisted beyond the stage of acute poisoning and that lead exposure is dangerous even at extremely low levels. ${ }^{2}$ The two primary environmental sources of lead exposure for the average child are leaded gasoline and lead-based paint.

Lead was first added to gasoline in the late 1920s to boost engine power, and the lead content of gasoline rose throughout the middle part of the century and remained high until the 1970s. According to the Environmental Protection Agency (EPA), in 1973 gasoline represented "the most ubiquitous source of lead found in the air, dust, and dirt in urban areas." ${ }^{3}$ In 1974, under the authorization of the Clean Air Act, the EPA mandated a timetable for the reduction of lead in gasoline, requiring petroleum companies to meet certain targets of maximum grams of lead per gallon of gasoline. The average lead content of the gasoline produced by each refinery was to be reduced from 2.0 grams per total gallon to a maximum of 0.5 grams per total gallon by 1979 . Over the next few years, the time-table was delayed slightly and further reductions were implemented. This phase-out was extremely successful, and gasoline lead dropped by $99 \%$ 
between 1975 and $1990 .^{4}$

Lead from gasoline can be absorbed directly from breathing in gasoline exhaust from the air and also indirectly from contact with lead deposits that have accumulated in soil. During the years when high levels of lead were used in gasoline, blood lead levels were highly correlated with gasoline lead consumption in the previous two months. ${ }^{5}$ The National Health and Nutrition Examination Survey (NHANES) also confirmed that the massive reduction of lead emissions from gasoline between 1975 and 1990 was closely associated with corresponding large reductions in the blood lead levels of Americans. ${ }^{6}$ For the entire population, the mean dropped from $16 \mu \mathrm{g} / \mathrm{dL}$ in 1976 to only $3 \mu \mathrm{g} / \mathrm{dL}$ in 1991 . This decline occurred uniformly across all demographic groups, including age, race, income, and urban vs. non-urban residence: the entire distribution shifted downward. Among children age 1 to 5, in 1976 nearly 90\% had blood lead levels exceeding 10 $\mu \mathrm{g} / \mathrm{dL}$, while by 1990 more than $90 \%$ had blood lead levels below $10 \mu \mathrm{g} / \mathrm{dL} .^{7}$

Lead in paint is the second major source of environmental lead exposure, but it is not as readily absorbed as lead from gasoline nor did it experience such drastic changes. The lead content of paint declined relatively smoothly from 1920 on, with breaks in 1950 when lead-based paint was banned for interior use and in 1978 when it was banned for all residential uses. The primary danger since 1970 stems from older housing with deteriorating paint. ${ }^{8}$ Children absorb lead from paint sources directly when they eat paint chips or indirectly when deteriorating paint creates lead dust. ${ }^{9}$

In summary, lead exposure from gasoline and paint sources was significant throughout this century, until federal legislation in the 1970 s essentially eliminated first-hand exposure. ${ }^{10}$ The decline in lead exposure from gasoline sources between 1975 and 1985, resulting from the Clean Air Act, will be the main source of identification for the current analysis. Leaded gasoline was the 
major source of lead exposure for the general population from the 1950s to the 1980s, also the primary source of large state-specific changes in lead exposure, and therefore provides the best opportunity to identify the effects of lead exposure. ${ }^{11}$

\section{Lead and Crime}

The association between low-level lead exposure during early development and subsequent deficits in cognitive development and behavior is widely accepted. A large and diverse literature in epidemiology, psychology, and neuroscience reaches the consensus that early childhood lead exposure negatively affects cognitive development and behavior in ways that increase the likelihood of aggressive and antisocial acts. ${ }^{12}$

\section{$\underline{\text { A. Lead and behavior }}$}

Higher lead levels have been associated with aggressive behavior, impulsivity, hyperactivity, attention impairment, "minimal brain damage," and attention deficit and hyperactivity disorder (ADHD). ${ }^{13}$ These effects are present for all lead levels, for exposure from the prenatal period through early childhood, and for cognitive and behavioral performance of all age groups from infants to teenagers. It is generally agreed that early childhood exposure (before age 6) is most harmful to psychological development, and that these effects persist to a great degree. ${ }^{14}$ Coscia et al [2003] argue that by contributing to weak verbal, reading, and other abilities, lead exposure “deflects such youth's development in an antisocial direction." Many studies have found higher lead levels among children who are hyperactive or have other behavior problems. ${ }^{15}$ Needleman and Bellinger [1981] report that children with above-average (but still moderate) lead levels are more than three times as likely to be distractible, hyperactive, impulsive, and to have low overall functioning. ${ }^{16}$ 
Cellular and animal studies indicate that lead affects neurological function in two ways: it has irreversible effects on the development of the central nervous system, as well as possibly reversible effects on the day-to-day operation of the nervous system. Most importantly, lead exposure during critical stages of development appears to impair brain development by disrupting the orderly formation of networks of neurons, a process that is important for normal behavior. ${ }^{17}$ Lead can also disrupt neurotransmitter function in ways that impair cognition and reduce impulse control. Results from animal studies show that lead exposure disrupts social behavior in ways that would impair inhibitory processes and produce hyperactivity, impulsivity, and attention disorders in humans. These studies also indicate that exposure early in life generally has more severe and persistent effects on cognition and behavior than later-life exposure. ${ }^{18}$

\section{B. Behavior and crime}

There is also significant evidence that individuals who exhibit aggression, impulsivity, or ADHD are more likely to commit antisocial and criminal acts. The link between aggression and antisocial behavior is obvious. With regard to impulsivity, Loeber [1990] argues that decreased levels of impulse control by American children are largely responsible for the increasing prevalence of antisocial and delinquent behavior among juveniles. Richardson [2000] writes that "offenders with ADHD often commit impulsive crimes," that "the ADHD brain has problems putting on the brakes and controlling actions," and that "rage and violence are often life-long problems for people with untreated ADHD."19 Two studies on groups of teenagers find that children with ADHD are five times more likely to be delinquent than children without ADHD. ${ }^{20}$ Another study finds that children with ADHD are five times more likely to be convicted of any crime by age 30 and twelve times more likely to be convicted of a violent crime. ${ }^{21}$ Currently, ADHD and other impulsivity disorders are so prevalent among juvenile delinquents and adult 
criminals that they are a major focus of concern among criminologists and criminal psychologists. C. Lead, IQ, and crime

Increased lead levels are also associated with decreased mental skills, including reduced IQ, reduced verbal competence, increased reading disabilities, and reduced academic performance. ${ }^{22}$ The effect on IQ has been debated extensively, but the consensus is that an increase in blood lead level of $1 \mu \mathrm{g} / \mathrm{dL}$ produces a decrease of approximately one-half of an IQ point, without any safe threshold. ${ }^{23}$ This means that two children who are otherwise identical but whose lead levels differ by $15 \mu \mathrm{g} / \mathrm{dL}$ (approximately the decline in lead levels between 1976 and 1990) would exhibit an average IQ difference of 7.5 points. Lower IQ can then be linked to criminal behavior: although highly controversial, a representative estimate is that criminal offenders have IQs about 10 points below non-offenders on average. ${ }^{24}$

\section{Lead, delinquency, and crime}

Lead has also been associated directly with delinquent, criminal, and aggressive behavior. Denno [1990] finds that lead poisoning is the most significant predictor of disciplinary problems and one of the most significant predictors of delinquency, adult criminality, and the number and severity of offenses. Needleman et al. [1996] find a significant relationship between the amount of lead in bone (a good measure of past exposure) and antisocial, delinquent, and aggressive behaviors. Dietrich et al. [2001] followed a cohort of 195 inner-city youths from birth through adolescence, and found a clear linear relationship between childhood blood lead levels and the number of delinquent acts. In addition, Needleman et al [2002] showed that adjudicated delinquents were four times as likely to have high lead levels than non-delinquents, and several studies have shown that violent criminals exhibit higher levels of lead in their bodies than nonviolent criminals or the general population. ${ }^{25}$ Lastly, two studies have used U.S. data to show a 
strong association between lead exposure and crime rates: Nevin [2000] does this with a national time-series, while Masters et al. [1998] employ a cross-section of counties. ${ }^{26}$

\section{E. Summary}

Thus, the evidence shows that lead is associated with aggressivity, impulsivity, ADHD, and lower IQ, and that these impairments in turn are associated with violent and criminal behavior. $^{27}$ Lead has also been directly associated with delinquent and criminal behavior. Although the U.S. Centers for Disease Control (CDC) have successively lowered the "acceptable" blood lead level (from $40 \mu \mathrm{g} / \mathrm{dL}$ in 1970 , to $30 \mu \mathrm{g} / \mathrm{dL}$ in 1975 , to $25 \mu \mathrm{g} / \mathrm{dL}$ in 1985 , to $10 \mu \mathrm{g} / \mathrm{dL}$ in 1991) these guidelines have barely kept pace with the level of medical knowledge. While the blood lead levels of most American children have always been officially acceptable, they have also been high enough to reduce IQ and cause behavior problems that could persist into adulthood. The links to aggressivity, impulsivity, and crime just described pertain even at the moderate lead levels $(10-20 \mu \mathrm{g} / \mathrm{dL})$ common in the U.S. in the 1970s and earlier. There are sound reasons to hypothesize a link at the national level between higher lead exposure as a child and a higher likelihood of committing impulsive or violent crimes as an adult.

\section{$\underline{\text { F. Predicted size of the effect }}$}

It is possible to approximate the magnitude of these effects by performing several quick calculations. First, I can follow the link from lead to ADHD to crime. Using lead-hyperactivity estimates from Needleman and Bellinger [1981] together with ADHD-delinquency/crime estimates from Dalsgaard [2003], Satterfield [1987], and Moffitt \& Silva [1988], I find an elasticity of delinquency or criminal behavior with respect to lead of $0.5 .^{28}$ This elasticity is substantial and significant. Second, I can follow the link from lead to reduced IQ to more crime. Using blood lead levels from the NHANES, lead-IQ estimates from Canfield et al [2003], and IQ- 
crime estimates from Herrnstein and Murray [1996], I find an elasticity of the likelihood of being

stopped by the police with respect to lead of $0.06{ }^{29}$ This elasticity is certainly small, but it is important to note that it only follows the IQ link, not any other aspects of behavior. Third, I can follow the link from blood lead levels to juvenile delinquency. To do this, I use the data reported by Dietrich et al [2001] and calculate an elasticity of the number of delinquent acts with respect to an individual's blood lead level of 0.5 to $1.0{ }^{30}$ This elasticity is calculated on a sample of innercity, primarily black youths with high rates of juvenile delinquency, and so is not directly generalizable to the larger population. Overall, these preliminary calculations, based on limited samples with possible endogeneity, suggest an elasticity of crime with respect to lead of between 0.06 and 1.00. The analysis below will use the lead reduction resulting from the Clean Air Act to identify a causal link between lead and crime. I now proceed to discuss the empirical framework and measurement of lead exposure.

\section{Empirical Framework and the Measurement of Lead Exposure}

\section{$\underline{\text { A. Empirical Framework }}$}

The ultimate goal of this paper is to identify a causal effect of lead on crime: are individuals who were exposed to more lead as children more likely to commit crimes as adults? Ideally, one would estimate an equation that models the propensity to commit a crime as a function of childhood blood lead, preferably with some source of exogenous variation in childhood blood lead:

$$
\text { Prob }(\text { crime })=\alpha_{1} \text { childhood blood lead }+ \text { other factors }+\varepsilon .
$$

While data is not available to estimate this equation, data is available to estimate a closely related equation that models the propensity to commit a crime as a function of childhood lead exposure : 


$$
\text { Prob }(\text { crime })=\alpha_{1} \text { childhood lead exposure }+ \text { other factors }+\varepsilon \text {. }
$$

In addition, the Clean Air Act directly influenced the lead content of gasoline, thereby providing random variation in childhood lead exposure. Furthermore, limited data is available to test the implicit first-stage relationship between childhood lead exposure and childhood blood lead:

$$
\text { childhood blood lead }=\alpha_{1} \text { childhood lead exposure }+ \text { controls }+\varepsilon \text {. }
$$

Thus, this paper will estimate equation 2 , and will verify the validity of using that equation by also estimating equation 3 .

\section{B. Measuring Lead}

Gasoline lead is released into the environment from the exhaust pipe of a car, but its effects on child development do not occur until it is absorbed into a child's body. A chain of events links the source to a child, and the empirical analysis of this paper must do that as well. Several sources of data provide the opportunity to take a multi-faceted approach to this challenge. First, measures of blood lead in children are available, but only for the years 1976 to 1980 . While not usable as a primary lead measure, the blood lead data can be used to test the validity of other measures. Second, measures of lead released by automobile sources - the grams of lead per gallon of gasoline - are available for the entire period 1950 to 1990 . This will be the primary measure: it is attractive because it is simple and was the target of EPA regulation. Third, measures of lead in the air are available for the period 1960 to 1990, but measurement problems limit their usefulness. I now discuss the various lead measures in turn.

\section{$\underline{1 . \text { Blood lead levels }}$}

Blood lead levels measure the concentration of lead in blood directly, in micrograms per decileter of blood $(\mu \mathrm{g} / \mathrm{dL}) .{ }^{31}$ National data on blood lead levels comes from the National Health and Nutrition Examination Survey (NHANES). The NHANES II measured blood lead levels of 
9,372 individuals of all ages (including 2,322 children age 0 to 5) in the years 1976 to 1980 . Because of the limited years, these data cannot provide the temporal and geographic coverage necessary for the primary analysis in this paper. However, these data do cover a time period -- the central portion of the phase-out of lead from gasoline -- during which there was substantial variation in lead exposure and levels, and will consequently provide an excellent opportunity to test the validity of implicit first-stage. As discussed above, the NHANES data confirm that blood lead levels dropped drastically as lead was phased out from gasoline. ${ }^{32}$

\section{Gasoline lead exposure}

Gasoline lead exposure is a measure of the lead content of gasoline. Using geographically detailed data on the lead concentrations in different grades of gasoline and the shares of those grades used in each state, I construct a measure of the average grams of lead per gallon of gasoline in each state in each year for the years 1950 to 1990. Prior to 1973, nearly all gasoline was leaded and gasoline was broken down into regular, premium, and sometimes super-premium grades. Once unleaded gasoline was introduced (in 1971-2), there were four basic grades of gasoline: regular unleaded, premium unleaded, regular leaded, and premium leaded. The distinction between the different grades is based on octane, and since lead is an octane enhancer the lead content varied across grades: premium leaded gasoline contained significantly more lead than regular leaded gasoline. Furthermore, because of the manner of distribution of gasoline throughout the country, the lead content of each grade of gasoline and the amounts consumed of the different grades also differed significantly from state to state. ${ }^{33}$

Using data on the shares and grams per gallon of each grade, I calculate the average grams of lead per gallon of gasoline in a given state in a given year by summing over grades the product of the share of that grade and the grams per gallon of that grade: 


$$
\text { Grams per gallon }(s, y)=\sum_{\text {grades } g}[\text { share of grade }(s, y, g) \times \text { gpg of grade }(s, y, g)]
$$

This measure is called gasoline lead exposure, and it measures the grams of lead per gallon of gasoline.

As shown in Table 1, the national mean of gasoline lead exposure was 2.0 grams per gallon (gpg) in the period 1965 to 1980 , and it declined by $72 \%$ in the 1970 s, dropping to near zero by $1990 .^{34}$ Figure 1 displays the rise and fall of lead exposure for selected states, showing large rises before 1970 and steep declines in the late 1970s. Appendix Table 1 provides more detail for each state during the phaseout, and shows that there is significant variation across states in the timing and size of these substantial declines in lead exposure.

There are three reasons why the variation in grams per gallon is well-suited to the current analysis: i) the changes in grams per gallon were indirectly induced by EPA policy; ii) EPA policy specifically targeted grams per gallon; iii) EPA policy was imposed on petroleum companies, not states. Consequently, not only is the cross-state variation in the phaseout best observed in grams per gallon, but the variation resulted not from state government policy or state-specific EPA policy but rather from a variety of features of the petroleum industry. The network of petroleum pipelines delivered gasoline with different lead contents to different regions of the country. Even within a region, the lead content of different grades of gasoline (regular, midgrade, premium, superpremium) differed significantly (by as much as 50\%). Demand for the different grades of gasoline also varied with consumer preference and with the age of the stock of cars (which also varied with climate). Even the number of gasoline pumps available at gas stations affected the path of the introduction of unleaded gasoline, and particularly the phase-out of high-lead premium gasoline between 1979 and 1980. Thus, grams of lead per gallon appears to have experienced substantial and largely random reductions in the period 1975 to 1985 , reductions that varied 
significantly from state to state and that were indirectly induced by EPA policy. ${ }^{35}$

The gasoline data come from several sources. The shares of the different grades of gasoline are from the Yearly Report of Gasoline Sales by States for the years 1976 to 1984, published by Ethyl Corporation, and from the Petroleum Marketing Annual for the years 1985 to 1989, published by the U.S. Department of Energy. The grams of lead per gallon for the different grades of gasoline are from the Petroleum Products Survey for the years 1947 through 1989, published by the U.S. Department of Energy. ${ }^{36}$

\section{$\underline{\text { 3. Per-capita lead exposure }}$}

It is possible that, by paying closer attention to the mechanism of exposure to gasoline lead, one might potentially improve upon grams per gallon. Because people are exposed to lead from gasoline sources when a car using leaded gasoline drives past them, other factors may modify the effect of grams per gallon on an individual's lead exposure. For example, the effect of any given level of grams per gallon might be dampened in a state with little driving or amplified in a state that is very densely populated. Essentially, individual lead exposure depends not only on (i) how much lead is in the gas, but also on (ii) the amount of driving and (iii) the density of exposure to driving. While gasoline lead content accounts for (i), it does not account for (ii) or (iii).

One could propose correcting for these oversights by generating alternate measures of gasoline lead predicated on particular mechanisms for lead exposure. To account for (ii) the intensity of driving, we can multiply the gasoline lead content by total gallons of gasoline and divide by population to produce a measure of per-capita lead exposure: grams of lead per person. Unfortunately, this makes the assumption that lead is a purely private bad when in reality it has some public characteristics: a single gram of lead released on a crowded city street will certainly 
affect more people than the same gram released on a deserted country road. For a high-population and high-density state like New York, the consequences of this mistaken assumption could be severe: not only does dividing by a large population produce an artificially low estimate of lead exposure, but failing to adjust for the high population density exacerbates this bias. These problems are likely to crop up for the highest population states (California and New York lead substantially) and the highest population density states (New York and the District of Columbia lead by far). As shown in Appendix Table 2, New York has the second-highest population and the single highest population density by a large margin. ${ }^{37}$ Because of this, New York ranks lowest on per-capita lead, even though it ranks only twelfth-lowest in grams per gallon and the population is densely packed and probably exposed to significant automobile exhaust. This issue would certainly encourage caution in the use of per-capita lead as a measure of lead exposure.

These problems could possibly be addressed, correcting for (iii) the density of exposure to driving by multiplying per-capita lead exposure by the average population density in which people live. ${ }^{38}$ However, this requires a complex density calculation and introduces yet another bias by mistakenly assuming that population density directly translates into driving exposure density, when we could reasonably expect a declining marginal effect of population density on driving density. Thus, while modified gasoline lead measures may have merits, they also make problematic assumptions and consequently have potentially serious flaws.

However, while there is a reasonable expectation that these measures are biased in the cross-section, there is some indication that the gallons per capita correction may be important in the longer time series. Hilton and Levinson [1998] use international data to document the existence of an environmental Kuznets curve for lead. They show that lead first rises with income due to increasing use of gasoline (more polluting activity) and then falls with income due to the 
reduction of the lead content of gasoline (environmental quality is a normal good). This pattern is apparent in the U.S. data for 1950 to 2000: much of the rise in lead is explained by increasing gallons of gasoline per capita, while the fall in lead is entirely due to the reduction in grams per gallon. Consequently, the per-capita lead measure may be relevant in the longer time series.

\section{Air lead exposure}

EPA air monitoring data provides another possible measure of lead exposure, supplying information on the lead content of the air people breathe. Since the 1960s, the EPA's Aerometric Information Retrieval System (AIRS) has used individual monitors to measure the levels of various pollutants and particulates at locations throughout the United States. Through a Freedom of Information Act request, I obtained a data file with the average lead reading within each quarter of each year for each monitor for the years 1960 to $2000 .{ }^{39}$ Monitor locations are chosen so that the readings should provide an accurate representation of the pollutant content of the air in a given county. By population-averaging the readings within a state, I construct a measure of the average concentration of lead in the air (measured in $\mu \mathrm{g} / \mathrm{m}^{3}$ ) in each state in each year. ${ }^{40}$ This measure is called air lead exposure.

Air lead exposure shows a time pattern similar to gasoline lead: in the period between 1965 and 1980 , the mean across all states of air lead exposure was $1.04 \mu \mathrm{g} / \mathrm{m}^{3}$, and it declined by $68 \%$ in the 1970s, dropping to near zero by 1990. This trend, and state-specific values, can be seen in Table 1, Figure 1, and Appendix Table 1.

While the air data have the potential to provide a good measure of individual lead exposure, the data are problematic for a number of reasons. First, many observations are missing, particularly in the 1960 s, during which time air lead observations are missing for nearly one-third of all state-year cells. ${ }^{41}$ Second, the monitors do not cover the entire area of each state uniformly - 
they cover less than half of the population of most states. Third, in most years the number of lead readings was too low to be deemed "representative" by the EPA. Fourth, monitors came in and out of operation, reducing the accuracy of the changes in lead exposure from year to year within a given state. ${ }^{42}$ In light of these serious problems, one might be tempted to ignore air lead altogether. However, air lead still provides valuable (if flawed) information on the lead content of the air people breathed in different states at different times. While it may not be sufficiently wellmeasured to be used when state and year fixed effects are included, it may be relevant when making purely cross-sectional comparisons, when testing robustness of other lead measures, or as part of an instrumental variables strategy. I will use air lead, but do so cautiously and with awareness of its weaknesses, eliminating the most unreliable measurements and interpolating for missing observations as appropriate.

\section{Instrumenting for air lead with gasoline lead}

In order to make use of the unique information air lead provides on lead exposure without succumbing to its numerous measurement problems, I will use gasoline lead as an instrument for air lead. Gasoline lead has the potential to provide a good instrument: it is highly correlated with available air lead data, is available for all states and all years, has much less measurement error, and was the target of regulation. The first stage will use only the actual air lead measures (no interpolated values) and will eliminate extreme and unreliable values.

Table 2 shows the coefficient on gasoline lead in the first-stage OLS regression of air lead on gasoline lead for the time period 1965 to 1985. The baseline coefficient is 0.337 (standard error 0.023 ), and is relatively robust to specification checks. Weighting the regression by state population increases the coefficient slightly, and including state and year fixed effects attenuates the coefficient slightly and increases the standard error substantially. Additional sensitivity tests 
do not provide substantially new information. ${ }^{43}$ When state and year fixed effects are added to the weighted regression, the coefficient is 0.465 with a standard error of 0.203 . These larger standard errors do raise concerns that grams per gallon may be a weak instrument for air lead in a state panel. Thus, this instrumental variables strategy will be used cautiously, and primarily as a sensitivity check.

\section{Verifying the first stage}

I now test the validity of these lead measures by investigating whether the available measures of lead exposure actually predict blood lead. I consider gasoline lead first. Others have reported that gasoline lead exposure and blood lead levels are highly correlated. ${ }^{44}$ I perform OLS regressions of blood lead on gasoline lead on the sample of individuals with blood lead measures in the NHANES II in the 1976-1980 period. In this sample, blood lead and gasoline lead can be linked by month and year: the NHANES II data contain the exact date on which the blood sample was taken and the gasoline data is available monthly during this period. Table 3 shows these results: column 1 includes only the simple lead measure, column 2 adds individual-level demographics, and column 3 includes state fixed effects and year fixed effects. This specification is:

(5) Blood Lead (i,s,y,m) $=\alpha_{1}$ gasoline lead $(i, s, y, m)$

$+\alpha_{2}$ age $(i, y, m)+\alpha_{3}$ race $(i)+\alpha_{4}$ gender $(i)+\alpha_{5}$ income category (i)

+ state fixed effects + year fixed effects $+\varepsilon$

where $m$ is the month of observation. The final regression in column 4 allows the effect of lead to vary by age. Column 1 shows that gasoline lead is a strong predictor of blood lead: one gram of lead per gallon of gasoline increases blood lead by $3.32 \mu \mathrm{g} / \mathrm{dL}$. By this measure gasoline lead is able to explain half of the change in average blood lead between 1976 and $1980 .^{45}$ This relationship is robust to the inclusion of individual covariates and weakens slightly upon the 
inclusion of state and year fixed effects. Most importantly, the last column shows that the effect of lead exposure on blood lead is strong and robust for young children but declines with age. Results are similar in a specification using the log of gasoline lead. Overall, it appears that gasoline lead, measured as grams per gallon, is strongly related to children's blood lead levels.

We can gain further insight into the relative value of the available lead measures by testing each measure against children's blood lead. The results in Table 4 indicate that gasoline lead, percapita lead, and the instrumented air lead all show a robust relationship with children's blood lead, even after inclusion of individual demographics and state and year fixed effects. The elasticity of children's blood lead with respect to the lead measures are relatively precisely estimated at 0.55 for gasoline lead, 0.30 for per-capita lead, and 0.74 for the instrumented air lead (in the specification with state and year fixed effects). Air lead shows a slight relationship, but it is much smaller, less significant, and not robust. For all of the measures, removing the three highpopulation and high-density states (states that raise potential problems in the appropriate measurement of lead exposure) increases the estimated elasticities substantially. For gasoline lead, the elasticity rises to 0.84 .

Overall, the results in Table 4 confirm that all of the lead measures other than air lead are able to predict children's blood lead reasonably well. It is important to note that this analysis was performed on data from the period 1976 to 1980 only. The great advantage of this is that the existence of such detailed data for any period of time and in particular for the period of time during which lead was phased out from gasoline certainly provides a unique opportunity to test the validity of these lead measures. Indeed, it has validated gasoline lead, per-capita lead, and the instrumented air lead. On the other hand, the disadvantage is that the limited time period means that one should exercise caution extrapolating these results too vigorously beyond this time period. 
For air lead, in particular, the data in the late 1970s appear to be of much higher quality than data in earlier time periods, so the value of the air lead measure remains in question.

\section{$\underline{\text { D. Summary of lead measures }}$}

I have reviewed the available lead measures, both theoretically and empirically. Gasoline lead, measured as grams per gallon, will be used as the primary lead measure: it is simple, was the target of EPA regulation, and is a robust predictor of children's blood lead. At the same time, alternate measures may be useful as sensitivity checks, providing opportunities for testing robustness and possibly addressing deficiencies in grams per gallon.

\section{Empirical evidence on lead exposure and crime}

We now turn our attention to investigating the relationship between childhood lead exposure and adult criminal behavior at the national level. This investigation will use grams per gallon and the other lead measures discussed above, together with per capita crime rates for the United States from the Uniform Crime Reports compiled by the Federal Bureau of Investigation (available annually since 1960). The discussion first considers the national time series, the state cross section, and a differences-in-differences table. The ultimate and primary analysis uses a panel of state-year observations, and includes extensive robustness checks.

\section{$\underline{\text { A. National time series }}$}

The lead contents of gasoline and paint for the years 1900 to 1990 are shown in Figure 2. Total lead exposure peaked in the 1920s (due to paint) and again in the 1970s (due to gasoline) and declined drastically to nearly zero by 1990. Gasoline lead exposure rose until 1970 and then fell. The most drastic drop in lead from gasoline sources occurred between 1975 and 1985, when the amount of lead dropped by more than $90 \%$. 
Figure 3 presents per-capita crime rates for the years 1970 to 2002 for violent crime, property crime, and murder. (Violent crime consists of robbery, murder, aggravated assault, and rape. Violent crime is dominated by assault and robbery; murders represent less than $3 \%$ of violent crime. Property crime consists of burglary, larceny, and auto theft.) All three categories of crime rise to 1980 , decline, rise again to 1991 , and then decline. Violent crime shows this pattern most strongly, with a large increase before 1991, a peak between 1991 and 1993, and a large decline after 1993.

Figure 4 presents gasoline lead exposure for the years 1950 to 1988 together with total violent crime for the years 1972 to 2002 . The crime series is presented with a 22 -year lag relative to the gasoline lead exposure series because 22 years is the average age of violent criminals. The relatively close match between the series suggests a relationship between lead exposure in a given year and violent crime approximately 22 years later, supporting the hypothesis that higher childhood lead exposure is associated with higher adult crime rates. Furthermore, the earlier history also confirms this: violent crime rates were almost flat between 1950 and 1963, followed by a prolonged steep rise. This matches well with the introduction of lead into gasoline in the late 1920 s and the increase in lead content in the late 1930 s and early 1940 s.

\section{B. State cross-section}

A second way to examine the relationship between lead and crime is to look at the crosssectional variation. I do this by regressing log crime in each state in 1992 against the lead exposure in that state 22 years earlier. The results of this analysis are encouraging. For gasoline lead, the R-squared values are 0.10 for violent crime, 0.02 for property crime, and 0.18 for murder;

for air lead, these values are $0.26,0.14$, and 0.15 respectively. ${ }^{46}$ These results imply elasticities of 4.0 and 0.9 of violent crime with respect to gasoline lead and air lead respectively. Overall, this 
limited and preliminary analysis suggests a positive relationship between lead exposure and crime in the cross-section.

\section{$\underline{\text { C. Differences-in-differences }}$}

Another way to use state-to-state variation is to use a differences-in-differences analysis to compare how crime rates changed over time in high lead states versus low lead states. ${ }^{47}$ Since the lead content of gasoline began to decline in the early 1970s, we would not expect to see bigger decreases in crime in high lead states than in low lead states until the cohorts born in the early 1970s were old enough to commit crimes (at least 17). ${ }^{48}$ Differences should therefore show up from approximately 1990 on. However, since high lead states probably had larger increases in lead exposure in the 1950s, we might expect to see larger increases in crime in high lead states in the 1970s. Figure 5 displays the trends in violent crime for high lead states and low lead states for the entire period 1960 to 2000, showing that the high lead states exhibit a similar but amplified pattern of crime changes relative to the low lead states.

Table 5 shows the percent change in crime in five-year time periods from 1972 to 2002 for violent crime, property crime, and murder separately. It provides some support for an association between childhood lead exposure and crime. For the period 1992 to 1997, high lead states had differentially larger crime decreases for all three categories of crime (14.5 percentage points more for violent crime, 12.4 for property crime, and 21.2 for murder). Over the entire period 1985 to 2002, they experienced crime decreases that were differentially higher as well (27.7 percentage points more for violent crime, 20.4 for property crime, and an insignificant 17.0 for murder). Prior to 1990, the differences were not consistent in one direction and mostly insignificant. Overall, this preliminary differences-in-differences analysis provides some mild support for a link between lead and crime. States that experienced larger decreases in lead exposure in the 1970s 
appear to have experienced larger decreases in crime in the mid 1990s and throughout the period from 1985 to 2002, though the effect does not consistently carry through to the late 1990s.

\section{State-year panel data analysis}

The best way to determine the relationship between lead exposure in childhood and criminality in adulthood is to use a long panel of state-level observations. By using cross-state variation over time to identify the effect of lead exposure on crime, this approach makes best use of the state-level changes in lead exposure that resulted from the Clean Air Act.

\section{Calculating Effective Exposure Variables}

Before using the state-year panel, one further calculation is necessary to link lead exposure in early childhood to crime committed in adulthood. I define the effective lead exposure relevant to crime $c$ in state $s$ in year $y$ as the weighted average of early childhood (age 0 to 3 ) lead exposure across all cohorts of arrestees: ${ }^{49}$

$$
\begin{aligned}
& \text { Effective Lead }(c, s, y)= \\
& \qquad \begin{array}{c}
\sum_{\text {ages } a}\{[\operatorname{Lead}(s, y-a)+\operatorname{Lead}(s, y-a+1)+\operatorname{Lead}(s, y-a+2)+\operatorname{Lead}(s, y-a+3)] / 4 \\
x[\operatorname{Arrests}(c, a, 1985) / \operatorname{Arrests}(c, \text { total, 1985) }]\}
\end{array}
\end{aligned}
$$

This measure is calculated separately for each crime $c$ for the years 1985 to 2002 . The ratio of arrests for a given cohort to the total arrests gives the fraction of arrests involving members of that cohort. It is important to note that the age distribution for arrestees is not specific to the crime year or to the state but instead is taken from 1985 national numbers so that it is not affected by changing lead exposure. By weighting lead exposure in the prenatal year plus the first three years of life using the age distribution for potential offenders, this effective lead measure accurately represents the early childhood lead exposure of potential offenders. Consequently, it represents a measure of the critical lead exposure that could potentially affect crime rates in that state in that 
year. Note that, as shown, this measure implicitly assumes that individuals do not migrate from the state in which they were born. In fact, I do correct for cross-state migration using state-ofbirth distributions by age, year, and state of residence from the decennial U.S. censuses. Crossstate migration between birth and age 22 is generally in excess of $25 \%$, making it important to control for such migration in order to accurately link adults back to their childhood lead exposure. $^{50}$

\section{Specification}

The basic specification is a regression of the log per capita crime rate on the effective lead exposure in a panel of states for the years 1985 to 2002. The regressions include state fixed effects to control for any time-invariant state characteristics that might affect crime and year fixed effects to control for any national trends. Furthermore, to establish clearly the significance of lead exposure's effect on crime, I control for other possible determinants of crime rates. These include variables indicating the state of the economy and employment (unemployment rate, income per capita, and poverty rate), variables pertaining to law enforcement (prisoners per capita and police per capita in the previous year), and other variables that might affect crime rates (gun laws, beer consumption, AFDC generosity 15 years earlier, teen pregnancy rate in birth years, and the population age distribution). This list includes nearly all factors that have been considered as possible determinants of crime rates. In addition, I control for the "effective abortion rate" as

defined by Donohue and Levitt [2001]. ${ }^{51}$ Donohue and Levitt found significant and robust effects of the effective abortion rate on crime, concluding that the legalization of abortion can account for nearly $50 \%$ of the recent drop in crime. Their basic premise was that "children born after abortion legalization may on average have lower subsequent rates of criminality," either because women who have abortions are more likely to have children who would engage in criminal activity or 
because abortion enables a woman to choose to have a child when she is most able to provide a nurturing environment. Therefore, because it appears to be an important potential determinant of crime rates, I include the effective abortion rate as an additional control variable. ${ }^{52}$

Thus, the full regression equation is:

$$
\begin{aligned}
\ln (\text { crime per capita })(s, y)=\alpha_{1} \text { lead exposure }(s, y)+\alpha_{2} \text { abortion exposure }(s, y) \\
+ \text { state-level controls }(s, y) \beta \\
+ \text { state fixed effects }+ \text { year fixed effects }+\varepsilon
\end{aligned}
$$

This equation is estimated separately for the three different categories of crime (violent crime, property crime, and murder) on a panel of 51 states (including the District of Columbia) for the years 1985 to 2002. The measure of the crime rate is the log per capita crime rate calculated from the Uniform Crime Reports. Effective gasoline lead exposure and effective abortion exposure are calculated as described above. Standard errors are Huber-White robust and are clustered within each state to correct for serial correlation in the panel. ${ }^{53}$ Observations are weighted by state population so that the analysis is representative of the typical person in the United States.

\section{Main results}

The main results of the panel data regression analysis of crime on effective gasoline lead exposure (grams per gallon) are presented in Table 6. The table shows results for each of three crime categories (violent, property, and murder) in three specifications: with state and year fixed effects only, adding nearly all state-level covariates (not abortion), and finally adding effective abortion exposure. In all cases, the coefficients on lead exposure and abortion exposure are rescaled so that they represent elasticities of crime with respect to lead or abortion exposure. ${ }^{54}$

The table shows a significant effect of lead exposure on violent crime. The estimated elasticity for gasoline lead exposure is 0.976 (standard error 0.542) without controls. The coefficient drops somewhat upon the inclusion of controls for the economy, employment, law 
enforcement, and other factors, and drops to 0.785 (standard error 0.403) after controlling for abortion. Effective abortion exposure shows a significant elasticity of 0.22 for violent crime, which is slightly larger than the elasticity originally reported by Donohue and Levitt. Most of the other controls have the correct sign and insignificant coefficients: only police, guns, and beer consumption are significant.

These results suggest that childhood lead exposure is significantly associated with violent crime. Based on these estimates, the fall in gasoline lead would be responsible for a $56 \%$ drop in violent crime between 1992 and 2002. These results also imply that abortion legalization was responsible for a 29\% drop in violent crime between 1992 and 2002.

Turning to the other crime categories, Table 6 shows insignificant results. Childhood lead exposure does not appear to show a significant relationship with property crime or murder. Abortion exposure is significant for both property crime and murder, with elasticities of 0.14 and 0.23 respectively.

\section{$\underline{\text { 4. Sensitivity analysis }}$}

I test the robustness of the above results by employing alternate samples, specifications, functional forms, and lead measures. We will see that the violent crime results are robust, that there is still little evidence for a causal effect of lead exposure on property crime, but that there may be some evidence suggesting an effect of lead exposure on murder.

\section{a. Alternate samples and specifications}

Table 7 shows a variety of different specifications using effective gasoline lead exposure. The baseline specification includes state fixed effects, year fixed effects, all controls, and abortion (identical to columns 3,6, or 9 in Table 6). The next four rows exclude some states with either high population density or high population (New York and the District of Columbia have the 
highest densities by far, and California and New York have the highest populations, refer to Appendix Table 2). The following rows include state-specific linear trends and region-year interactions. The next group shows results of unweighted regressions and results when effective lead exposure is not corrected for cross-state migration (i.e., assuming individuals remain in the state in which they were born). The last two rows show results for a log-log, rather than loglinear, specification.

The results for violent crime are robust to nearly all of these sensitivity tests. In most specifications, the coefficients change slightly and remain significant, with elasticity estimates ranging between 0.7 and 1.1 and significance levels below 0.05 . When New York, California, and the District of Columbia are dropped from the sample individually or as a group, the point estimate rises substantially and becomes more significant. As discussed above, the fact that grams per gallon does not make specific adjustments for the density of individual exposure to lead may render it somewhat less accurate for dense or heavily populated states. Recalling that the average population density in New York and the District of Columbia are extremely high, it is not surprising that removing these states from the sample increases the estimated strength of the relationship between lead and crime. (Note also that this result is parallel to the blood lead results shown in Table 4, in which removing these states increased the estimated elasticity of blood lead with respect to gasoline lead.) Controlling for omitted factors with region-year fixed effects more than doubles the point estimate, yielding an elasticity of 1.81. Including state-specific trends reduces the coefficient substantially, increases the standard error, and yields an insignificant elasticity. This specification is identified using the residual variation of each state around its own time trend, and is likely to reduce the signal to noise ratio and increase attenuation bias. Removing the migration correction reduces the elasticity of violent crime with respect to gasoline 
lead to an insignificant 0.45 . This is not surprising, since migration of individuals from their birth state (generally $25-40 \%$ of the population will migrate out of state) introduces noise in the uncorrected effective lead measures by incorrectly assigning lead exposure to the portion of the population that switched states. Interestingly, this effect appears to be most important for the high population and high density states: when these states are dropped, the elasticity is significant and close to the baseline estimate even without the migration correction. The final rows, testing the possibility that the effect of lead exposure on crime has a functional form other than log-linear, show a significant elasticity of 0.79 in a $\log$ - $\log$ specification. ${ }^{55}$ Overall, the analysis in Table 7 shows that the relationship between lead and violent crime is robust to a variety of specification checks. $^{56}$

The sensitivity tests for property crime provide almost no evidence of any relationship. The coefficients are of varying sign and almost always insignificant.

The results for murder provide some mild evidence of a relationship. While the baseline estimate is insignificant, there is a significant elasticity of 1.08 of murder with respect to gasoline lead when high population and high density states are excluded. There are significant effects also when region-year fixed effects control for unobservables, and in most other specifications dropping these states. Further investigation reveals that this sensitivity arises almost entirely from New York and the District of Columbia, and may reflect the omission of crack cocaine, gangs, and guns from the analysis. These are potentially important factors affecting homicides in central cities in this time period, particularly in New York, as discussed in Maltz [1998] and Fagan et al. [1998]. ${ }^{57}$ It may also be useful to consider the possibility that access to and quality of hospital trauma care may have influenced murder rates (by saving the victim, thereby turning some murders into violent assaults, see Harris et al [2002]). While future work may be able to control 
for these influences explicitly, the current results do provide some weak support for the possibility that lead exposure may be linked to murder. ${ }^{58}$

\section{b. Alternate lead measures and alternate functional forms}

Gasoline lead (grams per gallon) has been used as the primary lead measure because it is simple, was the target of EPA regulation, and is a robust predictor of children's blood lead. At the same time, gasoline lead is not perfect and there are reasons why one might consider alternate lead measures. In Section IV, I discuss the advantages and disadvantages of these alternate measures. I also show that two alternate measures - per-capita lead and air lead instrumented by gasoline lead - join gasoline lead as robust predictors of children's blood lead in the late 1970s, while air lead does not. Now I investigate the sensitivity of the crime results to these alternate measures of lead exposure. I also take this opportunity to test robustness to functional form. Because of the centrality of population density and population in the choice of the appropriate lead measure, the table also shows results dropping just New York from the sample (high on both density and population) and dropping all three high-population and high-density states (New York, California, and the District of Columbia).

Table 8 shows these results for violent crime. The first column (largely reproducing results from Table 7) shows again that the results for gasoline lead (grams per gallon) are robust to dropping the three high-population and high-density states and to the log-log specification. This merely re-confirms the evidence in support of a strong relationship between gasoline lead and violent crime, and an elasticity estimated to be between 0.7 and 1.1. Moreover, analysis using a flexible spline at quartiles of lead exposure (shown in Appendix Table 3) yields significant and relatively stable coefficients throughout the range of lead exposure.

Results for the first alternate lead measure, per-capita lead, are shown in the second 
column of Table 8 . Recall that per-capita lead attempts to correct for the amount of driving in a state, but that it is likely biased downward for high-population and high-density states. Because it divides by a large population while also failing to adjust upward for high population density, this bias is likely to be particularly severe for New York, which has the second-highest population (a close second to California) and the highest population density (nearly three times that of any other state, excluding DC, and ten times the median state). Looking at the results, we see that per-capita lead shows insignificant effects in the linear specification for the full sample, but significant and large effects when New York is removed. Moreover, in a log-log specification per-capita lead shows significant effects for violent crime whether or not New York is included in the sample. Removing the District of Columbia and California has little effect. The spline produces significant results as well, with some indication of non-linearity when New York is included, but overall yielding relatively stable estimates over the range of lead exposure. Overall, the violent crime results using per-capita lead are extremely similar to those using gasoline lead, with estimated elasticities in the range of 0.7 to 1.1 and standard errors of 0.3 to 0.4 .

The next two columns show results for air lead and the instrumented air lead. Air lead, subject to many measurement problems and ineffective in predicting blood lead, is similarly ineffective in predicting violent crime. The estimated elasticities are much smaller (0.04 to 0.21$)$ and quite imprecisely estimated, and most are insignificant. Further investigation reveals that the few results that are significant are driven almost entirely by California. ${ }^{59}$ By contrast, the instrumented air lead, a good predictor of blood lead, shows strong and robust results in all samples and all specifications. Elasticity estimates lie between 1.0 and 1.4, slightly higher than those obtained using gasoline lead. This slight amplification of estimated coefficients in an IV specification is not surprising when the instrument may be somewhat weak. 
Similar sensitivity testing for murder (shown in Appendix Table 4) aligns with earlier results, yielding slight evidence in favor of a relationship between lead and murder. No significant results are observed in the full sample nor in the log-log specification for any of the lead measures. The only significant results are observed for grams per gallon, per-capita lead, and the instrumented air lead in the log-linear specification in the reduced sample. These elasticities are of the order observed elsewhere, between 0.7 and 1.3. Further investigation of non-linearity, using a spline at quartiles of exposure, points to an increasing marginal effect of lead on murder, with significant effects primarily in the fourth quartile of lead exposure. This may explain why a loglog specification, which imposes a decreasing marginal effect, shows weak results, while a loglinear specification produces some significant results. With regard to the exclusion of the three states, as discussed above they may be influential due to the omission from the analysis of certain other factors important to homicide rates: crack cocaine, guns, and gangs.

For property crime, there is again little evidence for any influence of lead exposure (results not shown). The log-log specifications do yield significant elasticities of 0.4 to 0.7 for all measures other than air lead, but these results are not robust to the removal of the three states.

\section{c. Overall assessment}

Overall, the above analysis provides strong support for a relationship between childhood lead exposure and violent crime. The results for violent crime are robust to numerous specification tests, with a baseline estimate of 0.79 and estimated elasticities ranging between 0.7 and 1.3 . In addition, supportive evidence is provided by the concordance between the earlier results testing the implicit first stage (Table 4) and these results testing the reduced form (Table 8): measures of childhood lead exposure that predict children's blood lead appear also to be strongly related to violent crime in adulthood. 
The results for murder are weak, though there is some mild supportive evidence. The sensitivity of the murder results to New York, the District of Columbia, and California cannot be overlooked, but is not entirely surprising given the potential importance of omitted factors such as gangs, crack, and guns for these states. The weak murder results could also stem from the rarity of murders (rendering identification more difficult), a weaker effect of lead on murder than on other violent behavior, or a different functional form for this relationship (such as an increasing marginal effect). Given that murder is the most violent of violent crimes, it is not unreasonable to hypothesize that only substantial exposure to lead will produce this extremely aggressive and violent behavior, while more moderate exposure will have more moderate effects. This would be in line with the spline results. In sum, while there is currently only weak evidence for an effect of lead on murder, and only in the reduced sample, future work will attempt to probe this relationship further.

Finally, the analysis provides little support for a relationship between lead exposure and property crime. This outcome is also relatively unsurprising. Given that the psychological mechanisms by which lead exposure may affect criminality involve a spectrum of impulsive, aggressive, and violent behaviors, it seems plausible that lead might have a substantial effect on violent crime but a smaller (or no) effect on property crime. The medical and psychology literatures include extensive evidence on the effect of lead on violent and aggressive behavior, including violent criminal behavior, but much less evidence indicating effects on non-violent property crimes.

\section{Interpretation}

Childhood lead exposure appears to be significantly related to adult violent crime. The 
central result from the above analysis is an elasticity of violent crime with respect to gasoline lead of 0.79 , with estimates ranging between 0.7 and 1.1 with standard errors of 0.3 to 0.4 . I now endeavor to assess the importance of this effect in influencing violent crime at the societal level.

\section{A. Accounting crime trends}

To understand the societal magnitude of these effects, I first consider the period from 1992 to 2002 , during which time violent crime declined by a third. The above results predict a $56 \%$ decline in the per capita violent crime rate due to reductions in lead exposure. At the same time, the increased effective abortion rate would reduce per capita violent crime by $29 \%$. Other factors (police, prisons, beer consumption, and crack) appear to be responsible for an approximate $23 \%$ decline. ${ }^{60}$

I can also look at a longer time frame, to examine both the rise and the decline in crime. In the earlier period from 1972 to 1992, violent crime went up 83\%. In this period, effective grams per gallon rose $19 \%$, which would lead to a $28 \%$ increase in violent crime. However, as discussed above, much of the rise in lead exposure came from increasing gasoline use rather than increasing lead content, so for this earlier period it may be more appropriate to employ changes in per-capita lead to estimate the effect of lead on crime. ${ }^{61}$ This yields an estimate of a $91 \%$ increase in violent crime due to increasing lead exposure. Abortion and other factors were relatively unimportant, but Levitt [2004] argues that the growth of prisons was responsible for a $35 \%$ reduction in violent crime during this period. ${ }^{62}$

Putting the pieces together, the long story is approximately as follows. From 1972 to 1992, violent crime rose $83 \%$ : increasing lead exposure produced a $28-91 \%$ increase, the growth of prisons produced a $35 \%$ decrease, and a remaining $24-87 \%$ increase remains unexplained. From 1992 to 2002, violent crime dropped 34\%: declining lead exposure produced a 56\% 
decrease, legalized abortion produced a $29 \%$ decrease, other factors produced a $23 \%$ decrease, and a remaining $74 \%$ increase remains unexplained. Thus, the current results imply that lead exposure was likely an important factor in both the rise and the decline of violent crime in the last 30 years. At the same time, the recent history of violent crime is not fully understood: a sustained rise in crime of about $3-5 \%$ annually remains unexplained.

Lastly, we can ask what these results may imply about future trends in crime. This projection should be undertaken with caution: not only will unknown and unpredictable factors certainly influence crime in the coming decades, but the effect of childhood lead exposure may be different at the lower levels relevant to coming cohorts. ${ }^{63}$ With those caveats in mind, I make the following tentative predictions. By the year 2020, when the effects of the Clean Air Act and Roe v. Wade would be complete, violent crime could be as much as $70 \%$ lower than it would be if lead had remained in gasoline, and as much as $35-45 \%$ lower than it would be if abortion had never been legalized. At the same time, history suggests that other unknown factors would have increased crime by perhaps 3-5\% per year.

\section{B. Benefits of crime reduction}

Another way to assess the magnitude of these impacts is to compare the social costs of the removal of lead from gasoline to the benefits in the form of crime reductions. The costs of the removal of lead from gasoline are discussed at length in the 1985 EPA report Costs and Benefits of Reducing Lead in Gasoline: Final Regulatory Impact Analysis. ${ }^{64}$ The report uses a linear programming model of refinery behavior to estimate the social costs of lead reduction regulations. The model estimates that the marginal manufacturing cost differential between leaded gasoline containing 1.10 grams per gallon and unleaded gasoline was less than 3 cents per gallon. This value matches well with estimates based on inter-refinery trades of lead permits ( 3 to 4 cents per 
gallon) as well as spot prices of gasoline (2 to 6 cents per gallon differential). I use these values, together with the more detailed cost estimates in the report, to estimate that the cumulative social cost for the period 1970 to 1995 of the switch to unleaded gasoline was between 15 and 65 billion dollars. $^{65}$

To calculate the social value of crime reductions, I employ estimates of the monetary and quality of life costs of violent crimes from Cohen [1988] and Miller, Cohen, and Rossman [1993]. Monetary costs include lost productivity, lost property, and medical bills, while quality of life costs attempt to capture pain and suffering (by estimating from jury awards). In these estimates, the average violent crime incurs $\$ 3,600$ of monetary costs and $\$ 54,700$ of quality of life costs. ${ }^{66}$ I combine this with the estimated reductions in violent crime that are attributable to lead exposure for the period 1990 to 2020 (from $0 \%$ rising to $70 \%$ ), producing an estimate of 1.2 trillion dollars ( $\$ 75$ billion monetary and $\$ 1.2$ trillion quality of life).

Comparing the costs and benefits, we see that the cost of the removal of lead from gasoline is similar in size to the monetary value of the resultant reduction in violent crime, and is approximately twenty times smaller than the full value (including quality of life) of the crime reductions. This implies that the removal of lead from gasoline can be justified almost entirely by its benefits in the form of reductions in violent crime, even without taking account of lead's effects on any number of other behaviors or health outcomes.

\section{Extensions}

The relationship between lead and violent crime has further implications. First, this may contribute to explaining rural-urban differentials in crime rates as well as the cross-sectional relationship between crime and city size. Larger cities have much higher per-capita crime rates, and Glaeser and Sacerdote [1999] account for half to three-quarters of this gap by the differential 
deterrence, returns to crime, and individual characteristics. If cities with high population density also have higher lead exposure, lead could be an important additional factor. Second, lead may be a factor in explaining crime rates by race or income. If disadvantaged groups live in denser and more polluted neighborhoods, they will experience higher lead exposure as children and therefore exhibit more criminal behavior as adults. It may be possible to use the indices of segregation outlined by Cutler, Glaeser, and Vigdor [1999] to test this hypothesis. Third, lead may explain and predict certain cross-national patterns of crime and other behaviors. Hilton and Levinson [1998] use international data to document the existence of an environmental Kuznets curve for lead. If lead pollution rises with income and then declines, the current results imply that violent crime would also rise with income and then decline, but with a 22-year lag. There would be a crime Kuznets curve, as well as Kuznets curves for other social behaviors possibly affected by lead exposure such as substance abuse, teenage pregnancy, and suicide. Further work will investigate these and other hypotheses.

\section{Conclusion}

This paper shows a significant and robust relationship between lead exposure in childhood and violent crime rates later in life. The estimates indicate that the reduction in lead exposure in the 1970s is responsible for a $56 \%$ drop in violent crime in the 1990 s and will likely produce further declines in the future, up to a $70 \%$ drop in violent crime by the year 2020 . The legalization of abortion, as identified by Donohue and Levitt, remains an important and significant factor. Thus, two major acts of government, the Clean Air Act and Roe v. Wade, neither intended to have any effect on crime, may have been the largest factors affecting violent crime trends at the turn of century. These results emphasize the importance of accounting for earlier life influences when 
explaining adult behavior. While there is some evidence supporting an effect of lead on murder, there is no evidence for an effect on property crime.

While the results herein imply that lead could be one of the most important factors influencing violent crime in the United States, this effect on crime may be just the tip of the iceberg. Increases in impulsivity, aggression, and ADHD can affect many other behaviors such as substance abuse, suicide, teenage pregnancy, poor academic performance, poor labor market performance, and divorce. Future research will investigate these outcomes, and further explore the potentially far-reaching effects of environmental policy. 


\section{References}

Alan Guttmacher Institute, 1992. Abortion Fact Book, 1992 ed., ed. S. Henshaw and J.V. Vort, Alan Guttmacher Institute: New York, NY.

Banks, E.C., L.E. Ferretti, and D.W. Shucar, 1997. "Effects of Low Level Lead Exposure on Cognitive Function in Children: A Review of Behavioral, Neuropsychological, and Biological Evidence," Neurotoxicology, 18(1), p. 237-281.

Bellinger, David, April 2004. "Lead," Pediatrics, 113(4), p. 1016-1022.

Bertrand, M., E. Duflo and S. Mullainathan, 2004. "How Much Should We Trust Differences-inDifferences Estimates?," Quarterly Journal of Economics, 119(1), p. 249-75.

Brody, D.J., et al., 1994. "Blood Lead Levels in the US Population, Phase One of the Third National Health and Nutrition Examination Survey (NHANES III 1988-1991)," JAMA, 272(4), p. 277-283.

Bryce-Smith, D., 1983. "Lead Induced Disorders of Mentation in Children," Nutrition and Health, 1, p. 179-194.

Canfield, R. L. et al., 2003. "Intellectual Impariment in Children with Blood Lead Concentrations below 10 mcg per Deciliter," New England Journal of Medicine, 348(16), p. 1517-1526.

Cohen, M.A., 1988. "Pain, Suffering, and Jury Awards: A Study of the Cost of Crime to Victims," Law and Society, 22(3), p. 537-555.

Cork, D., 1999. "Examining Space-Time Interaction in City-Level Homicide Data: Crack Markets and the Diffusion of Guns Among Youth," Journal of Quantitative Criminology, 15(4), p. 379406.

Cory-Slechta, D., 1989. "The Lessons of Lead for Behavioral Toxicology," in Lead Exposure and Child Development: An International Assessment, M. Smith, L. Grant, and A. Sors, Editors. Kluwer Academic: Boston, MA. p. 399-413.

Coscia, J.M., et al, 2003. "Cognitive Development of Lead Exposed Children from Ages 6 to 15 Years: An Application of Growth Curve Analysis," Child Neuropsychology, 9(1), p.10-21.

Culbertson, J.L. and K.R. Krull, 1996. "Attention Deficit Hyperactivity Disorder," in Neuropsychology for Clinical Practice: Etiology, Assessment, and Treatment of Common Neurological Disorders, R.L. Adams, O.A. Parsons, and e. al., Editors. American Psychological Association: Washington, D.C. p. 271-330.

Cutler, D., E. Glaeser and J. Vigdor, 1999. "The Rise and Decline of the American Ghetto," Journal of Political Economy, 107 p. 455-506. 
Dalsgaard, S., 2003. "Long-term psychiatric and criminality outcome of children with attentiondeficit/hyperactivity disorder," Nordic Journal of Psychiatry, 57(2): p.160.

Davis, J.M. and D.J. Svendsgaard, 1987. "Lead and Child Development," Nature, 329(6136), p. 297-300.

Denno, D.W., 1990. Biology and Violence: From Birth to Adulthood, New York, NY: Cambridge University Press.

Dietrich, K., et al., 1987. "The Neurobehavioral Effects of Early Lead Exposure," in Toxic Substances and Mental Retardation: Neurobehavioral Toxicology and Teratology, S.R. Schroeder, Editor. American Association on Mental Deficiency: Washington, D.C. p. 71-95.

Dietrich, K.N., et al., 1991. "Lead Exposure and the Cognitive Development of Urban Preschool Children: The Cincinnati Lead Study Cohort at Age 4 Years," Neurotoxicology and Teratology, 13(12), p. 203-211.

Dietrich, K. N., R. M. Douglas, et al., 2001. "Early exposure to lead and juvenile delinquency," Neurotoxicology and Teratology, 23(6), p. 511-518.

Donohue, J.J., 1998. "Understanding the Time Path of Crime," The Journal of Criminal Law and Criminology, 88(4), p. 1423-1451.

Donohue, J.J., III and S.D. Levitt, 2001. "The Impact of Legalized Abortion on Crime," Quarterly Journal of Economics, 116(2), p. 379-420.

Donohue, J.J. and S. D. Levitt, 2004. "Further Evidence that Legalized Abortion Lowered Crime: A Reply to Joyce," Journal of Human Resources, 39(1), Winter 2004, p. 29-49.

DuPont Petroleum Chemicals, 1973. Road Octane Survey, Winter 1972-73: Wilmington, DE.

Ethyl Corporation, 1976-1984. Yearly Report of Gasoline Sales by States. Ethyl Corporation: Houston, TX.

Fagan, Jeffrey, F. Zimring, J. Kim, 1998. "Declining Homicide in New York City: A Tale of Two Trends" The Journal of Criminal Law and Criminology, 88(4), p.1277-1324.

Federal Bureau of Investigation, annual. Uniform Crime Reports for the United States, Washington, D.C.: U.S. Government Printing Office.

Feldman, R.G. and R.F. White, 1992. "Lead Neurotoxicity and Disorders of Learning," Journal of Child Neurology, 7(4), p. 354-359.

Fishbein, D.H., 2000. The Science, Treatment and Prevention of Antisocial Behaviors: Application to the Criminal Justice System, Civic Research Institute: Kingston, New Jersey. 
Fryer, Roland, P.S. Heaton, S.D. Levitt, and K.M. Murphy, 2005. "Measuring the Impact of Crack Cocaine," National Bureau of Economic Research Working Paper No. 11318, Cambridge, Massachusetts.

Gibbs, L.M., 1990. "Gasoline Additives - When and Why" in International Fuels and Lubricants Meeting and Exposition. Tulsa, OK: SAE International.

Gibbs, L.M., 1993. "How Gasoline Has Changed" in Fuels and Lubricants Meeting and Exposition. Philadelphia, PA: SAE International.

Gibbs, L.M., 1996. "How Gasoline Has Changed II - The Impact of Air Pollution Regulations" in International Fall Fuels and Lubricants Meeting and Exposition. San Antonio, TX: SAE International.

Glaeser, E. L. and B. Sacerdote, 1999. "Why is There More Crime in Cities?" The Journal of Political Economy, 107(6) Part 2: Symposium on the Economic Analysis of Social Behavior in Honor of Gary S. Becker, p. S225-258.

Goldstein, P., H. Brownstein, et al, 1997. "Crack and Homicide in New York City: A Case Study in the Epidemiology of Violence" in Crack in America: Demon Drugs and Social Justice. C. Reinarman and H. Levine, Editors. Berkeley: University of California Press, p. 113-30.

Grogger, J. and M. Willis, 2000. "The Emergence of Crack Cocaine and the Rise in Urban Crime Rates," Review of Economics and Statistics, 82(4), p. 519-29.

Hammond, P. B., 1988. "Metabolism of Lead" in Lead Absorption in Children. J. J. Chisholm and D. M. O'Hara, Editors. Baltimore: Urban and Schwartzenberg.

Harris, A. R., et al, 2002. "Murder and Medicine: The Lethality of Criminal Assault 1960-1999," Homicide Studies, 6(2), p. 128-166.

Herrnstein, R.J. and C. Murray, 1996. The Bell Curve, New York: Simon \& Schuster.

Hilton, F.G. and A. Levinson, 1998. "Factoring the Environmental Kuznets Curve: Evidence from Automotive Lead Emissions," Journal of Environmental Economics and Management, 35, p. 126-141.

Joyce, Ted, 2004. "Did Legalized Abortion Lower Crime?" Journal of Human Resources, 39(1), Winter 2004, p. 1-28.

Joyce, Ted, 2004. "Further Tests of Abortion and Crime," National Bureau of Economic Research Working Paper No.10564, Cambridge, Massachusetts.

Levitt, Steven, 2004. "Understanding Why Crime Fell in the 1990s: Four Factors that Explain the Decline and Six that Do Not," Journal of Economic Perspectives, 18(1), Winter 2004, p. 163190. 
Liu, Xianchen, K. Dietrich, et al., 2002. "Do Children with Falling Blood Lead Levels Have Improved Cognition?," Pediatrics, 110(4), p. 787-791.

Loeber, R., 1990. "Development and Risk Factors of Juvenile Antisocial Behavior and Delinquency," Clinical Psychology Review, 10, p. 1-41.

Lott, J.R., Jr. and D.B. Mustard, 1997. "Crime, Deterrence, and Right-to-Carry Concealed Handguns," Journal of Legal Studies, 26(1), p. 1-68.

Maltz, Michael D., 1998. "Which Homicides Decreased? Why?" The Journal of Criminal Law and Criminology, 88(4), p.1489-1496.

Masters, R., B. Hone, et al., 1998. "Environmental Pollution, Neurotoxicity and Criminal Violence," in Environmental Toxicology: Current Developments. J. Rose. Amsterdam, Netherlands, Gordon \& Breach Science Publishers, p. 1-61.

Masters, R. D., 2001. "Biology and Politics: Linking Nature to Nurture," Annual Review of Political Science, 4, p. 345-369.

McCabe, P.P., 1991. "Low Level Lead Toxicity," Childhood Education, 68(2), p. 88-92.

Miller, T.R., M.A. Cohen, and S.B. Rossman, 1993. "Victim Costs of Violent Crime and Resulting Injuries," Health Affairs, 12(4), p. 186-197.

Moffitt, T.E. and P.A. Silva, 1988. "Self-Reported Delinquency, Neuropsychological Deficit, and History of Attention Deficit Disorder," Journal of Abnormal Child Psychology, 16(5), p. 553569.

National Cancer Institute, 2006. Surveillance, Epidemiology, and End Results (SEER) Program Public-Use Data 1973-2003 (www.seer.cancer.gov). NCI Surveillance Research Program: Bethesda. November 2005 data submission.

National Center for Health Statistics, U.S. Department of Health and Human Services. Second National Health and Nutrition Examination Survey, (NHANES II), 1976-1980. Hyattsville, MD: Centers for Disease Control and Prevention.

National Institute for Petroleum Energy Research and BETC, 1947-1989. Motor Gasoline Survey, Summer and Winter. U.S. Department of Energy.

National Institute for Petroleum Energy Research and BETC, 1982. Trends in Motor Gasolines: 1942-1981. U.S. Department of Energy.

Needleman, H., 1985. "The Neurobehavioral Effects of Low-Level Exposure to Lead in Childhood," International Journal of Mental Health, 14(3), p. 64-77. 
Needleman, H., 1995. "Environmental Lead and Children's Intelligence," British Medical Journal, 310(6989), p. 1408.

Needleman, H., et al., 1979. "Psychological Performance of Children with Elevated Lead Levels," New England Journal of Medicine, 300(13), p. 689-695.

Needleman, H., et al., 1979. "Deficits in Psychologic and Classroom Performance of Children with Elevated Dentine Lead Levels," New England Journal of Medicine, 300(13), p. 689-695.

Needleman, H., et al., 1990. "The Long-Term Effects of Exposure to Little Doses of Lead in Childhood: An 11 Year Follow-up Report," New England Journal of Medicine, 322(2), p. 8388 .

Needleman, H. and D.C. Bellinger, 1981. "The Epidemiology of Low-Level Lead Exposure in Childhood," Journal of the American Academy of Child Psychiatry, 20, p. 496-512.

Needleman, H. and C. Gatsonis, 1990. "Low-Level Lead Exposure and the IQ of Children: A Meta-analysis of Modern Studies," JAMA, 263(5), p. 673-678.

Needleman, H. and B. Gatsonis, 1991. "Meta-analysis of 24 Studies of Learning Disabilities due to Lead Poisoning," JAMA, 265, p. 673-678.

Needleman, H., et al., 1996. "Bone Lead Levels and Delinquent Behavior," JAMA, 275(5), p. 363369.

Nevin, R., 2000. "How Lead Exposure Relates to Temporal Changes in IQ, Violent Crime, and Unwed Pregnancy," Environmental Research, 83(1), p. 1-22.

Nriagu, J., 1990. "The Rise and Fall of Leaded Gasoline," Science of the Total Environment, 92, p. 13-28.

Pirkle, J., et al., 1994. "The Decline in Blood Lead Levels in the United States: The National Health and Nutrition Examination Surveys (NHANES)," JAMA, 272(4), p. 284-291.

Ruggles, S., M. Sobek, et al., 2003. Integrated Public Use Microdata Series: Version 3.0. Minneapolis, University of Minnesota.

Satterfield, J.H., 1987. "Childhood Diagnostic and Neurophysiological Predictors of Teenage Arrest Rates: An Eight-Year Prospective Study," in The Causes of Crime: New Biological Approaches, S.A. Mednick, T.E. Moffitt, and S.A. Stack, Editors. Cambridge University Press: New York, NY. p. 146-167.

Schwartz, J., 1994. "Low Level Lead Exposure and Children's IQ: A Meta-Analysis and Search for a Threshold," Environmental Research, 65(1), p. 42-55.

Schwartz, J. and H. Pitcher, 1989. "The Relationship Between Gasoline Lead and Blood Lead in 
the United States," Journal of Official Statistics, 5(4), p. 421-431.

United States Bureau of the Census, 2003. Migration and Geographic Mobility in Metropolitan and Nonmetropolitan America: 1995 to 2000. U.S. Census Bureau: Washington, D.C.

U.S. Environmental Protection Agency, 1973. EPA Requires Phase-Out of Lead in All Grades of Gasoline. U.S. EPA: Washington, D.C.

U.S. Environmental Protection Agency, 1985. Costs and Benefits of Reducing Lead in Gasoline: Final Regulatory Impact Analysis. U.S. EPA, Office of Policy Analysis, Washington, D.C.

U.S. Environmental Protection Agency, 1991. Lead Content of Gasoline 1967-1991. U.S. EPA,: Washington, D.C.

U.S. Environmental Protection Agency, 1995. Report on the National Survey of Lead-Based Paint in Housing: Base Report. U.S. EPA: Washington, D.C.

U.S. Environmental Protection Agency, 1998. National Emissions Trends, 1900 to 1998. U.S. EPA, Office of Air Quality Planning and Standards: Research Triangle Park, NC.

U.S. Environmental Protection Agency, 2003. Aerometric Information Retrieval System Quick Look Reports 1960-2000 for Lead, Office of Air Quality Planning and Standards: Research Triangle Park, NC.

United States Department of Energy and Energy Information Administration, 1985-1990. Petroleum Marketing Annual. U.S. DOE, Office of Oil and Gas: Washington, D.C.

United States Geological Survey and U.S. Department of the Interior, 1904-1929. Mineral Resources of the United States.

United States Geological Survey and U.S. Department of the Interior, 1933-1980. Minerals Yearbook.

United States Geological Survey and U.S. Department of the Interior, 2001. U.S. Consumption of Lead in Manufacture of Gasoline Additives, 1941-1986.

United States Department of Health and Human Services, 1950 to 1990. Vital Statistics of the United States. National Center for Health Statistics: Hyattsville, MD.

Wilson, J. and J. Petersilia, Eds., 1995. Crime. San Francisco, Institute for Contemporary Studies. 


\section{Data Appendix}

\section{Gasoline Data}

\section{Shares of grades of gasoline}

The primary data for shares of grades of gasoline for the years 1956 to 1984 come from the Yearly Report of Gasoline Sales by States. Ethyl Corporation was the primary manufacturer of the tetraethyl lead additive for gasoline, and published monthly and annual marketing reports for the petroleum industry. The data show gasoline sales reported to Ethyl Corporation by oil refiners manufacturing more than $95 \%$ of motor gasoline consumed in the United States. I use the data for motor gasoline sales only, and do not use the separate data on aviation fuels.

Data for the years 1956 to 1971 come directly from the Yearly Report of Gasoline Sales by States for the year 1976. The 1976 report contains historical data on the share of premium gasoline in each state in each year from 1956 to 1976 . Unleaded gasoline was not introduced until 1971-2, so the share premium completely defines the shares of existing grades of gasoline (leaded non-premium and leaded premium) in the years prior to 1972.

Data for the years 1972 to 1975 are calculated from the Yearly Report of Gasoline Sales by States for the year 1976. Unleaded non-premium (regular) gasoline was introduced on a very small scale in 1971-1972. However, for the years 1972 to 1975 the available Ethyl reports only tabulate the shares of non-premium and premium grades: they do not show the shares of unleaded non-premium and leaded non-premium separately for the years 1972 to 1975 . The report does show the exact shares in 1976. I therefore make an ad hoc calculation (as advised by individuals in the petroleum industry) for the years 1972 to 1975 using the following method. First, I place states into three categories based on the share unleaded represents of non-premium gasoline in that state in 1976 [ = share unleaded non-premium / (share unleaded non-premium + share leaded nonpremium ) ]. These three categories are: share unleaded of non-premium less than $20 \%$, share between 20\% and 28\%, and share above $28 \%$. (The mean share was $23 \%$.) This produces three groups of almost equal size. I then assume that the low group introduced unleaded non-premium gasoline in 1973, the middle group introduced unleaded non-premium gasoline in 1972, and the high group introduced unleaded non-premium gasoline in 1971. For each state, I start the state at $0 \%$ share in the year in which I assume it introduced unleaded non-premium, and then linearly trend it up to the 1976 share available in the Ethyl data. I assume the share of unleaded premium is zero in these years, which is reasonable since unleaded premium was definitely not introduced in any significant amount before 1976, and was primarily introduced between 1979 and 1981 .

Data for the years 1976 to 1984 come directly from the Yearly Report of Gasoline Sales by States for the years 1976 to 1984 . The report in each year contains the shares of unleaded gasoline, leaded non-premium, and leaded premium gasoline in each state in that year. (The 1981 report is the first to break unleaded gasoline into unleaded non-premium and unleaded premium, but that is not significant when calculating lead content since all unleaded gasoline contains virtually no lead.) The years 1976 to 1984 represent the main portion of the phase-out of leaded gasoline (more than $80 \%$ of the phase-out), so it is ideal that this time period also has the most detailed data on shares of grades of gasoline. It also includes monthly data.

Data for the years 1985 to 1990 are calculated from the Yearly Report of Gasoline Sales by States for the year 1984 and the Petroleum Marketing Annual for the years 1985 to 1989, 
published by the Energy Information Administration (EIA) of the Department of Energy. (The Ethyl reports stop in 1984, making it necessary to use a different source of data for the shares of different grades for the years 1985 to 1989.) The Petroleum Marketing Annuals for the years 1985 to 1989 show data on the sales to end-users of each grade of gasoline in each state in the years 1983 to 1989 . The sales are reported in thousands of gallons, and the grades reported are unleaded regular (unleaded non-premium), leaded regular (leaded non-premium), and premium (unleaded premium). By 1985, essentially all premium gasoline was unleaded: L.M. Gibbs [1993] writes that "leaded premium gasoline essentially disappeared in 1981." Consequently, the absence of a distinction between unleaded premium and leaded premium for the years 1983 to 1989 is not a problem, and the "premium" gasoline is assumed to be unleaded premium. From the EIA sales numbers, I calculate the share of each of these grades in each state in each year 1985 to 1989. I then calculate the percentage change from the previous year in the share non-premium leaded. To calculate the share non-premium leaded in the year 1985 in a state, I apply the percentage change between 1984 and 1985 (calculated from the EIA data) to the 1984 Ethyl share non-premium leaded. For each subsequent year, I calculate the share non-premium leaded using the percentage change from the previous year (calculated from the EIA data) applied to the share non-premium leaded calculated for the previous year. This procedure makes full use of the information the EIA data provides about the path over time of the share non-premium leaded, yet maintains a smooth transition and remains consistent with the Ethyl data. Examination of the shares calculated in this manner confirms that this is appropriate. It is also obvious that the shares of leaded gasoline were so low by 1985 that this calculation could not significantly affect the overall calculations.

\section{Grams of lead per gallon}

The grams of lead per gallon for the different grades of gasoline come from the Petroleum Products Survey: Motor Gasolines Winter and Petroleum Products Survey: Motor Gasolines Summer for the years 1947 through 1989, published by the National Institute for Petroleum Energy Research (NIPER) of the Department of Energy. These are measured from samples of motor gasoline sent to NIPER each year and are tabulated for 17 different districts in the United States. There is slight seasonal variation between winter and summer gasoline, so I use only the summer values for consistency except when analysis is done monthly. For the years 1947 to 1974, lead content (grams per gallon) is available separately for "regular" (leaded non-premium) and "premium" (leaded premium) grades. For the years 1975 to 1980, grams per gallon are reported for "unleaded" (unleaded non-premium), "regular" (leaded non-premium), and "premium" (leaded premium) grades. For the year 1981, grams per gallon are reported for "leaded below 93 octane" (leaded non-premium) and "leaded above 93 octane" (leaded premium) grades. For the years 1982 to 1989, grams per gallon are reported only for the "leaded below 93 octane" (leaded nonpremium) grade. According to individuals at NIPER, there was so little leaded premium gasoline by 1982 that it was no longer sampled. L.M. Gibbs [1993] writes that "leaded premium gasoline essentially disappeared in 1981."

I note that investigation of the data reveals that the lead contents for years prior to 1975 are actually for leaded non-premium and leaded premium grades even though they are called simply "regular" and "premium" grades. It does not appear that any unleaded gasoline was included in these samples. When unleaded gasoline was sampled, starting in 1975, it was broken out separately. (No excess decline in lead content is observed in the years 1972 to 1974 that would indicate that unleaded gasolines were included in these measurements prior to 1975.) 
The NIPER reports therefore provide the grams per gallon for each grade of gasoline for each year 1947 to 1989 in each of the 17 districts. From the listing of districts provided in the reports, I determine in which district a state lies and use the appropriate grams per gallon numbers for that state.

\section{Gallons of gasoline consumed}

The total gallons of gasoline taxed in each state in each year are available from the Federal Highway Administration for the years 1950 to 1995. Values are available for Alaska and Hawaii only after they became states in 1959. Therefore, for the years 1950 to 1958 for Alaska and Hawaii, I calculate the state's total gallons by calculating the year-to-year growth rate of total gallons for the other 48 states for the years 1950 to 1959 and applying these growth rates backwards to the 1959 gallons for the state.

\section{Population and population density}

State populations and population densities are calculated from the decennial U.S. Censuses, using tract-level data. These were accessed as the Integrated Public Use Microdata samples provided by the University of Minnesota. The average population density within which people in a state live is calculated as the population-weighted average of population density across census tracts in the state and year $=\sum_{\text {tracts } t}[$ pop of tract $(t, y) /$ pop of state $(s, y)] \times$ [ pop density $(t, y)$ ] where population density is measured in people per square mile.

\section{Per-capita lead}

Per-capita lead is defined as: Per Capita Lead (s,y) = Grams of Lead per Gallon (s,y) x Total Gallons (s,y) / Population (s,y).

\section{$\underline{\text { Air Lead Data }}$}

Air lead data come from the EPA's Aerometric Information Retrieval System (AIRS). The AIRS data, obtained through a Freedom of Information Act request, include quarterly readings of air lead concentrations at designated monitors throughout the United States. These data are available starting in 1960. I use a data file with the average lead reading within each quarter of each year for each monitor for the years 1960 to 2000. Air lead concentration is measured in

$\mu \mathrm{g} / \mathrm{m}^{3}$, and the AIRS data reports the second maximum average quarterly mean of lead for each monitor in each quarter for which there were measurements. Air lead exposure for a state-year is the weighted average of all lead measures for counties in that state in that year, using county populations as the weight. Many states have incomplete or missing data (as discussed in the text). Counties without monitors or lead readings are omitted when calculating the state average.

\section{Blood Lead Data}

Blood lead data is from the National Health and Nutrition Examination Survey (NHANES II). This survey was conducted by the National Center for Health Statistics, between 1976 and 1980, on a nationwide probability sample of approximately 28,000 persons 6 months through 74 years of age from the civilian, noninstitutionalized population of the United States. It also included physical examination and testing, including direct measures of blood lead concentrations 
on 10,049 individuals, 9,372 of whom were born in the United States and 2,322 of whom were under the age of 6 . These data include the blood lead concentration, the date the sample was taken, and basic individual demographics.

\section{Crime Data}

All crime data by state by year is from Uniform Crime Reports for the United States, published annually by the Federal Bureau of Investigation.

\section{State-level variables}

\section{Abortion}

Abortion rates are from the Statistical Abstract of the United States, published annually by the U.S. Bureau of Census. Abortion rates are measured as abortions per 1000 births. The original source of the data is The Abortion Fact Book published by The Alan Guttmacher Institute.

\section{Unemployment}

State unemployment rates are from the Statistical Abstract of the United States, published annually by the U.S. Bureau of Census. The unemployment rate represents the percent unemployed among civilian non-institutional population 16 years of age and older.

\section{Income}

Income per capita is from the Statistical Abstract of the United States, published annually by the U.S. Bureau of Census. It is converted into 2000 dollars.

\section{Poverty}

Poverty rates are from the Statistical Abstract of the United States, published annually by the U.S. Bureau of Census. The poverty rate is the percentage of the state population below the federal poverty line as defined in that year.

\section{Maternal characteristics}

Rates of teen pregnancy, mother with less than high school education, and no prenatal care in the first trimester are calculated from the Vital Statistics of the United States, published annually by the National Center for Health Statistics. The rate of teen pregnancy is calculated as all live births to women age 19 and under, divided by all live births. Share of mothers with less than high school education is calculated as number of mothers giving birth who have less than a high school education, divided by the total number of mothers giving birth. No prenatal care in the first trimester is calculated similarly.

\section{AFDC generosity}

Generosity of Aid to Families with Dependent Children (AFDC) is from the Statistical Abstract of the United States, published annually by the U.S. Bureau of Census. AFDC generosity is measured as the average yearly AFDC payment per family receiving aid (12 times the average monthly payment), lagged by 15 years and converted into 2000 dollars. 


\section{Prisoners}

Data on prisoners is from Correctional Populations in the United States, published annually by the Bureau of Justice Statistics. It is measured as prisoners per 1000 population and is lagged by one year.

\section{Police}

Data on police is from the Uniform Crime Reports for the United States, published annually by the Federal Bureau of Investigation. It is measured as police per 1000 population and is lagged by one year.

\section{Gun laws}

Data on gun laws is from Lott and Mustard [1997]. The variable indicates whether the state had a non-discretionary concealed handgun law in that year. Such a law requires local law enforcement authorities to grant concealed weapons permits to anyone meeting certain preestablished criteria.

\section{Beer consumption}

Beer consumption is from the Brewers Almanacs published by the Beer Institute. It is measured as consumption of malt beverages in gallons consumed per capita.

\section{Population age shares}

Population age shares are calculated from the Surveillance, Epidemiology, and End Results (SEER) Public-Use Data on the age distribution of the population, calculated and published by the National Cancer Institute. These data are used to calculate the shares of the population in each state that are in five-year age ranges between 15 years and 45 years. 


\section{Notes}

${ }^{1}$ Hammond [1988] reports that children absorb up to $50 \%$ of lead they ingest, compared with $8 \%$ for adults. Bellinger [2004] provides a good review of the differences in lead absorption between children and adults.

${ }^{2}$ It is important to distinguish between lead exposure and lead poisoning. Lead exposure is simply exposure to some level of lead. Lead poisoning encompasses a certain set of symptoms and occurs at particularly high levels of exposure (usually blood lead levels in excess of $25 \mu \mathrm{g} / \mathrm{dL}$ ). This paper is primarily concerned with lead exposure, not lead poisoning.

${ }^{3}$ U.S. Environmental Protection Agency, 1973.

${ }^{4}$ U.S. Environmental Protection Agency, 1998.

${ }^{5}$ Schwartz and Pitcher, 1989.

${ }^{6}$ U.S. Environmental Protection Agency, 1991; Brody, Pirkle, 1994.

${ }^{7}$ Pirkle, Brody, 1994. Since blood lead levels showed significant declines between 1976 and 1980, the figures comparing 1976-1980 levels to 1988-1991 levels probably underestimate the change. Indeed, NHANES data suggest that the blood lead levels of children age 1-5 declined from $18 \mu \mathrm{g} / \mathrm{dL}$ in 1976 to $2.8 \mu \mathrm{g} / \mathrm{dL}$ in 1991 .

${ }^{8}$ U.S. Environmental Protection Agency, 1995. The Department of Housing and Urban Development estimates that $83 \%$ of privately owned occupied housing units built before 1980 have lead-based paint somewhere and that more than $50 \%$ of housing units built before 1940 have dust and soil lead exceeding guidelines.

${ }^{9}$ Children eat paint chips because lead paint tastes sweet.

${ }^{10}$ Between 1975 and 1990, all measures of lead exposure (on-road vehicle emissions, other emissions, air lead, gasoline lead, and blood lead) declined drastically and in concert with one another. Between 1975 and 1990, total lead emissions declined by $97 \%$ and gasoline lead went from the dominant source of lead (80\% of emissions) to a minor source ( $8 \%$ of emissions). However, it is important to note that although first-hand exposure is currently low, the persistence of soil deposits means that dust and dirt in urban areas and paint in older houses still represent significant sources of lead in our environment.

${ }^{11}$ While deteriorating lead-based paint may currently be of great concern, the consensus is that, when gasoline was still leaded, gasoline provided much more lead for human exposure than paint. The basic reason for this is that gasoline lead is spewed into the air whereas paint lead mostly sits inertly on houses. In addition, while changes in paint lead exposure have been relatively small and gradual, changes in gasoline lead exposure were large and rapid between 1975 and 1985.

${ }_{13}^{12}$ Banks, Ferretti, 1997.

${ }^{13}$ Wilson and Petersilia, 1995; Needleman, 1990; Needleman, 1991; Banks, Ferretti, 1997.

${ }^{14}$ Bellinger, 2004; Needleman et al, 1996. Numerous studies find significant effects on teen and adult behavior using either early childhood blood lead or current bone lead (which indicates cumulative lifetime exposure.)

${ }^{15}$ Denno, 1990; Needleman, 1985.

${ }^{16}$ The study uses dentine lead levels, which are a good indicator of lifetime exposure. While the dentine lead levels cannot be directly compared to blood lead levels, the lead levels even for the high lead group in this study were relatively unremarkable in the 1970 s.

${ }^{17}$ Needleman et al [1996] report that lead exposure peaks between the ages of two and three, which is also when neuronal fibers are pruned.

${ }^{18}$ Banks, Ferretti, 1997.

${ }^{19}$ Fishbein, 2000.

${ }^{20}$ Both studies choose their sample to minimize selection bias and also control for socioeconomic status and other factors that might be related to delinquency and crime. Moffitt and Silva [1988] study a random group of 678 thirteen-year-olds. They report that children with ADHD at age 11 were more than five times as likely to be delinquent at age 13 than children without ADHD. In their study, 58\% of previously diagnosed ADHD children became delinquent, compared with only $10 \%$ of non-ADHD children. Satterfield [1987] compares 150 ADHD children with 88 normal control subjects. Satterfield finds that ADHD children were six times more likely to be arrested for at least one serious offense as a teenager.

${ }^{21}$ Dalsgaard, 2003.

${ }^{22}$ Bryce-Smith, 1983.

${ }^{23}$ Schwartz [1994] reports that an increase in blood lead level of $1 \mu \mathrm{g} / \mathrm{dL}$ produces a decrease of one-quarter of an IQ point. This estimate controls for socioeconomic and other factors that could affect IQ. Canfield et al [2003] report an 
effect of 0.8 of an IQ point per $1 \mu \mathrm{g} / \mathrm{dL}$ of blood lead in lower ranges, and an average effect of 0.46 . Furthermore, Liu et al [2002] report evidence that IQ deficits persist even after blood lead levels decline.

${ }^{24}$ Herrnstein and Murray, 1996. The controversy stems primarily from debate about appropriately establishing causality and controlling for socioeconomic factors and selection effects.

${ }^{25}$ Masters, 1998; Bryce-Smith, 1983.

${ }^{26}$ Both Nevin and Masters et al. show strong evidence linking lead and crime, but their data limitations (Nevin uses a single national time series, Masters et al. use a cross-section) do not allow them to control sufficiently for other confounders nor find exogenous variation in lead exposure and thereby establish causality. Masters et al. do present extensive physiological and individual-level evidence. They also present evidence highlighting the importance of interactions among lead, manganese, and alcohol.

${ }^{27}$ In many ways, the distinction between IQ and these other aspects of behavior as the intermediate factor is artificial. However, because of the independent significance of IQ in both academic and public discussion, it makes sense to separate the two pathways somewhat.

${ }^{28}$ This calculation proceeds as follows. Needleman and Bellinger [1981] report the relative prevalence in a low lead group and a high lead group of hyperactivity, impulsivity, distractability, and low overall functioning. Dalsgaard [2003], Satterfield [1987], and Moffitt and Silva [1988] each report the prevalence for a non-ADHD group and an ADHD group of delinquent or criminal behavior. High lead increases the likelihood of hyperactivity, impulsivity, and attention deficit by 2.7 times, and ADHD in turn increases the likelihood of delinquent or criminal behavior by 5-6 times. Using the lead and behavior levels in the samples, this yields an elasticity of 0.49 of delinquent or criminal behavior with respect to lead.

${ }^{29}$ This calculation proceeds as follows. NHANES data reports that children's average blood lead dropped from 18 $\mu \mathrm{g} / \mathrm{dL}$ to $3 \mathrm{mcg} / \mathrm{dL}$ between 1976 and 1990. Canfield et al report a slope of IQ with respect to blood lead of 0.74 per $1 \mu \mathrm{g} / \mathrm{dL}$ in the range 1 to $10 \mu \mathrm{g} / \mathrm{dL}$ and 0.125 in higher ranges. Herrnstein and Murray report data from the NLSY that yield an elasticity of being stopped by the police with respect to IQ of 0.75 , and also report a mean criminal IQ is 93. Using these values to following the path from lead to IQ to crime yields an elasiticty of 0.06 of being stopped by the police with respect to blood lead.

${ }^{30}$ This calculation proceeds as follows. NHANES data reports that children's average blood lead dropped from 18 $\mu \mathrm{g} / \mathrm{dL}$ to $3 \mu \mathrm{g} / \mathrm{dL}$ between 1976 and 1990. Dietrich et al [2001] report several regressions of the number of juvenile delinquent acts (self reports and parental reports) on several measures of blood lead. I use these reported coefficients (ranging from 0.090 to 0.194), together with the means of the data (average 3.5 delinquent acts), to calculate the elasticity of the number of delinquent acts with respect to blood lead.

${ }^{31}$ Bodily lead levels can be measured in a variety of ways. The most common are blood lead levels, dentine lead levels, and bone lead levels. A blood lead level is the concentration of lead in blood, and is measured in micrograms per deciliter $(\mu \mathrm{g} / \mathrm{dL})$ or micromoles per liter $(\mu \mathrm{mol} / \mathrm{L})$. A dentine lead level is the concentration of lead in teeth, and is measured in parts per million. Bone lead levels are measured similarly. Blood lead is a good measure of recent exposure, while dentine and bone lead are regarded as good indicators of cumulative lifetime exposure.

${ }^{32}$ The NHANES III measured blood lead levels of 26,818 individuals in the period 1988 to 1991, but the later time period renders these data not useful for the current analysis. By 1990, lead exposure and levels were extremely low, and what little lead exposure there was came almost entirely from non-gasoline sources (e.g. paint lead, industrial emissions, other emissions, or soil residue of past emissions). Consequently, the time period in which the NHANES III data was collected does not provide useful cross-state variation in gasoline lead exposure. Furthermore, the crossstate variation in the changes between 1975 and 1990 is almost entirely determined by the initial levels in the 1970s (already captured in the NHANES II data).

${ }^{33}$ Several examples of the variation in gasoline lead content include: In 1975, premium leaded gasoline contained 2.23 grams per gallon (gpg) while regular leaded gasoline contained 1.85 gpg. Also in 1975, regular leaded gasoline in Nebraska contained $1.85 \mathrm{gpg}$, and regular leaded gasoline in Mississippi contained $2.30 \mathrm{gpg}$. In 1977, the share for premium leaded gasoline was 13\% in Arkansas as compared with 32\% in California.

${ }^{34}$ The drop in childhood lead exposure in the 1970s implies that crime committing cohorts in the 1990s experienced a decline of $40-50 \%$ in their childhood lead exposure. This can be seen in the declines in "effective lead exposures," which are defined later in Section V.D.1.

${ }^{35}$ Gibbs, 1990, 1993, 1996, and personal communication.

${ }^{36}$ The details of the data sources and calculations are described in greater detail in the Data Appendix. 
${ }^{37}$ In New York, the average population density within which people live is much higher than other states: ten times the median among states, 1.8 times that in the District of Columbia (the second highest) and nearly three times that of the third highest state (New Jersey).

${ }^{38}$ Ideally, we would multiply the gasoline lead content by a measure of the amount and density of exposure to vehicular traffic. Unfortunately, the data that are available on cars owned or miles traveled have obvious systematic measure error: people in the suburbs own more cars, but have fewer cars pass them each day; people in the city own fewer cars, but have many more cars pass them each day. Thus, making the assumption that everyone within a state drives (or is driven) the same amount, the density of exposure to driving matches the density of population. Density of population can be calculated as the population-weighted average of population density (people per square mile) across census tracts in the state and year.

${ }^{39}$ Air lead concentration is measured in $\mu \mathrm{g} / \mathrm{m}^{3}$. The AIRS data reports the second maximum average quarterly mean of lead for each monitor in each quarter for which there were measurements. The EPA only began collecting these data in 1960, so no measurements are available prior to that year.

${ }^{40}$ Air lead exposure for a state-year is the weighted average of all lead measures for counties in that state in that year, using county populations as the weight. Counties without monitors or lead readings are omitted.

${ }^{41}$ Over the entire period 1960 to $1990,14 \%$ of state-year cells are missing air lead observations. The frequency of missing observations dropped over time: in the 1960 s, $30 \%$ of observations are missing; in the 1970 s $8 \%$ are missing; and in the $1980 \mathrm{~s} 5 \%$ are missing.

${ }^{42}$ Only seven states had one or more monitors that stayed in near-continuous operation from 1960 onward, and only 29 states had one or more monitors that stayed in near-continuous operation from 1965 onward. The number of monitors and readings increased substantially in the late 1970s. This means that air lead measures were much improved by the late 1970s, but also reduces the accuracy of within-state changes in lead exposure. There are also reports of inaccuracies and misreporting of EPA data in the 1970s.

${ }^{43}$ These tests include dropping other high population or high density states, dropping eleven states with very low lead measures in the early years (AK, AR, ID, KS, ME, MT, OR, RI, SC, SD, VA, VT, WY), and other sample restrictions. There is also little evidence of significant non-linearity.

${ }^{44}$ Schwartz and Pitcher, 1989.

${ }^{45}$ The actual reduction in blood lead between 1976 and 1980 was $6.5 \mu \mathrm{g} / \mathrm{dL}$. Changes in gasoline lead (from $1.8 \mathrm{gpg}$ to $0.7 \mathrm{gpg}$ ) predict a reduction of $3.4 \mu \mathrm{g} / \mathrm{dL}$ over this time period.

${ }^{46}$ For violent crime, 1 gram of gasoline lead increases violent crime by $158 \%$ (standard error $53 \%$ ) and $1 \mu \mathrm{g} / \mathrm{m}^{3}$ of air lead increases violent crime by $87 \%$ (standard error $23 \%$ ).

${ }^{47}$ States are categorized into high and low lead exposure by the size of the decrease in lead exposure between 1970 and 1980. High lead states are those whose change in lead exposure is in the top third of changes, low lead states are those whose change in lead exposure is in the bottom third of changes. The analysis is similar when states are categorized by the level in 1970 .

${ }^{48}$ High lead and low lead states are otherwise similar: comparing the means of observable variables (state-level covariates listed in Table 1) across these states shows few significant differences. Police and prisoners per capita show the only significant differences. Given that these crime prevention and criminal justice variables are unlikely to be orthogonal to crime, this is not surprising.

${ }^{49}$ This definition follows the definition of the "effective legalized abortion rate" in Donohue and Levitt [2001].

${ }^{50}$ Census data include state of residence, state of birth, and age, and consequently permit correction for cross-state migration when performing analysis at the state level. While it might be desirable to perform the analysis at the county level, such analysis would require data on cross-county but within-state migration (approximately $30 \%$, calculated from Census migration reports). Such data is not available, and the substantial cross-county within-state migration would introduce significant measurement error. Consequently, the data do not permit analysis at the county level.

${ }^{51}$ Abortion exposure is in units of abortions per 1000 births. Effective abortion exposure is calculated in a manner parallel to Equation 6, as defined by Donohue and Levitt [2001].

52 The effect of abortion exposure on crime has been debated by Joyce [2004a,b]. Donohue and Levitt [2004] respond to Joyce.

${ }^{53}$ Bertrand, Duflo, and Mullainathan, 2004.

${ }^{54}$ In a log-linear specification, multiplying the coefficient by the weighted mean of the independent variable yields the average elasticity in the sample. The weighted means for the sample are shown in Table 1. Standard errors are also rescaled by the means. 
${ }^{55}$ Additional results tested a quadratic, a linear spline with breakpoints at quartiles of effective lead exposure, and a linear spline with breakpoints at the $50^{\text {th }}, 75^{\text {th }}$, and $95^{\text {th }}$ percentiles. These specifications provide some mild evidence for a decreasing marginal effect of lead exposure on violent crime. Some of these results are discussed in the next section and shown in Appendix Table 3. However, all results on non-linearity should be considered with the caveat that the levels of lead exposure observed in this sample correspond to population blood lead levels between 10 and 20 $\mu \mathrm{g} / \mathrm{dL}$. Consequently, these results do not speak directly to the form or significance of the relationship at blood lead levels below $10 \mu \mathrm{g} / \mathrm{dL}$.

${ }^{56}$ The results are robust to a number of other sensitivity tests as well: excluding additional high-population or highdensity states (such as New Jersey); using only birth-year exposure rather than early childhood exposure; controlling for other maternal characteristics of the cohort (mother with less than high school education, no prenatal care in the first trimester); controlling for more detailed population age shares. Lastly, the inclusion of an interaction between lead and abortion does not significantly affect the results: the interaction term has a small, negative, and statistically significant coefficient, but it is not economically significant. Note that the expected direction and significance of the interaction between lead and abortion is unclear: if gasoline lead exposure is higher in poorer inner-city areas with higher population density, abortion and lead would amplify each other; however, if gasoline lead exposure is relatively uniform (as suggested by the NHANES II data), there may be no significant interaction.

${ }^{57}$ Levitt [2004], Goldstein et al [1997], Cork [1999], Grogger and Willis [2000], and Fryer, Heaton, Levitt, \& Murphy [2005] all discuss the importance of crack cocaine, particularly in New York and the District of Columbia. Fryer et al discuss the creation of a measure of crack cocaine usage. Fagan [1998] discusses the hypothesis that gangs and guns produced trends in homicides that differed from trends in violent crime more generally, and that this divergence was particularly important in New York City.

${ }^{58}$ Sensitivity testing for the effect of abortion on crime generally confirms its significance, with a few exceptions: in the unweighted specification, coefficients are smaller and insignificant; when state-year trends are included the coefficients are wrong-signed and large (and significant for property crime and murder); in the log-log specification dropping three states the coefficients are smaller, and significant only for property crime.

${ }^{59}$ Additional analysis using the most reliable air measures (on the 29 states that have at least one monitor that is in nearly continuous operation from 1965 onward) provides no improvement. It yields a larger elasticity in the full sample, but this result is similarly fragile.

${ }^{60}$ The current results support a role for police and beer consumption (4\% decline each), and Levitt [2004] presents evidence that the growth in prisons was responsible for a $12 \%$ decrease and the decline in crack usage (and associated violence) was responsible for a $3 \%$ decrease.

${ }^{61}$ Hilton and Levinson provide evidence on an Environmental Kuznets Curve for lead, as discussed previously. In addition, recall that results for per-capita lead are very similar to those using grams per gallon, with the exception of sensitivity to the inclusion of New York.

${ }^{62}$ Levitt [2004] estimates the effects of other factors between 1973 and 1991 as follows: increases in the number of police, $-3 \%$; the rise of crack, $+8 \%$; legalized abortion, $-2 \%$.

${ }^{63}$ In the period 1992 to 2002, the childhood lead exposure of the adult U.S. population declined by about half, approximately from $18 \mu \mathrm{g} / \mathrm{dL}$ to $10 \mu \mathrm{g} / \mathrm{dL}$. The remaining half of the decline, to less than $3 \mu \mathrm{g} / \mathrm{dL}$, will occur from 2002 to 2018. Most neurotoxins show a "hockey-stick" effect, with a much lower marginal effect below some threshold. Research does not show evidence of a clear threshold for lead, but it is certainly plausible. If there is a declining marginal effect for lead on crime, the predicted crime reductions would be lower. The $70 \%$ violent crime decline quoted in the paper is calculated assuming that the elasticity below $10 \mu \mathrm{g} / \mathrm{dL}$ is approximately half of that estimated in the paper. Not making that assumption, the decline would be $83 \%$.

${ }^{64}$ EPA, 1985, Chapter II.

${ }^{65}$ All dollar values are reported in year 2000 dollars.

${ }^{66}$ The monetary costs of the average violent crime in each category (in thousands of 2000 year dollars) are: murder 21.8 , rape 12.6, assault 2.3, robbery 3.7 ; and the quality of life costs are: murder 3,462, rape 52.3, assault 13.1, robbery 19.1. The share each crime category represents of violent crime is: murder 0.01 , rape 0.06 , assault 0.64 , robbery 0.29 . 
Table 1. Summary of Variables.

\begin{tabular}{|c|c|c|c|c|c|c|c|}
\hline \multirow{2}{*}{$\frac{\text { Variable }}{\text { Total lead from gasoline (kilotons) }}$} & \multicolumn{2}{|c|}{$1965-1980$} & \multicolumn{2}{|c|}{1970 only } & \multicolumn{2}{|c|}{1980 only } & \multirow{2}{*}{$\begin{array}{c}\% \Delta 70-80 \\
-68 \%\end{array}$} \\
\hline & 7.63 & $(5.46)$ & 9.67 & $(6.65)$ & 3.08 & $(1.91)$ & \\
\hline Gasoline lead (grams per gallon) & 2.00 & $(0.62)$ & 2.60 & $(0.16)$ & 0.72 & $(0.12)$ & $-72 \%$ \\
\hline Per-capita lead (kilograms per person) & 0.94 & $(0.30)$ & 1.20 & $(0.25)$ & 0.37 & $(0.10)$ & $-69 \%$ \\
\hline Air lead $\left(\mu \mathrm{g} / \mathrm{m}^{3}\right)$ & 1.04 & $(0.61)$ & 1.23 & $(0.54)$ & 0.40 & $(0.13)$ & $-68 \%$ \\
\hline Variable & 1985 & 2002 & 1990 & only & 2000 & only & $\% \Delta 90-00$ \\
\hline \multicolumn{8}{|c|}{ Effective gasoline lead exposure (grams per gallon) } \\
\hline Violent crime & 1.27 & $(0.36)$ & 1.58 & $(0.10)$ & 0.80 & $(0.09)$ & $-49 \%$ \\
\hline Property crime & 1.25 & $(0.47)$ & 1.64 & $(0.11)$ & 0.65 & $(0.07)$ & $-60 \%$ \\
\hline Murder & 1.19 & $(0.30)$ & 1.45 & $(0.09)$ & 0.80 & $(0.09)$ & $-45 \%$ \\
\hline \multicolumn{8}{|c|}{ Effective per-capita lead exposure (kilograms per person) } \\
\hline Violent crime & 0.58 & $(0.17)$ & 0.69 & $(0.13)$ & 0.42 & $(0.10)$ & $-39 \%$ \\
\hline Property crime & 0.59 & $(0.22)$ & 0.76 & $(0.15)$ & 0.35 & $(0.08)$ & $-55 \%$ \\
\hline Murder & 0.54 & $(0.14)$ & 0.62 & $(0.11)$ & 0.43 & $(0.10)$ & $-31 \%$ \\
\hline \multicolumn{8}{|l|}{ Effective air lead exposure $\left(\mu \mathrm{g} / \mathrm{m}^{3}\right)$} \\
\hline Violent crime & 0.62 & $(0.28)$ & 0.79 & $(0.34)$ & 0.47 & $(0.16)$ & $-41 \%$ \\
\hline Property crime & 0.59 & $(0.29)$ & 0.85 & $(0.35)$ & 0.40 & $(0.12)$ & $-53 \%$ \\
\hline Murder & 0.59 & $(0.26)$ & 0.72 & $(0.32)$ & 0.47 & $(0.16)$ & $-36 \%$ \\
\hline \multicolumn{8}{|c|}{ Effective abortion exposure (abortions per 1000 births) } \\
\hline Violent crime & 124 & $(120)$ & 47 & $(42)$ & 235 & $(110)$ & $402 \%$ \\
\hline Property crime & 179 & $(140)$ & 102 & $(77)$ & 289 & $(130)$ & $183 \%$ \\
\hline Murder & 95 & $(100)$ & 22 & $(26)$ & 199 & $(100)$ & $822 \%$ \\
\hline \multicolumn{8}{|l|}{ Crime rate (crime per 1000 population) } \\
\hline Violent crime & 6.26 & $(2.65)$ & 7.32 & $(3.13)$ & 5.06 & $(1.70)$ & $-31 \%$ \\
\hline Property crime & 44.81 & $(11.74)$ & 50.88 & $(11.70)$ & 36.18 & $(8.01)$ & $-29 \%$ \\
\hline Murder & 0.077 & $(0.041)$ & 0.094 & $(0.051)$ & 0.055 & $(0.026)$ & $-42 \%$ \\
\hline State unemployment rate & 5.7 & $(1.57)$ & 5.5 & $(0.83)$ & 4.0 & $(0.78)$ & $-27 \%$ \\
\hline State personal income per capita & 26674 & (3963) & 25785 & (3655) & 29760 & (4105) & $15 \%$ \\
\hline Poverty rate & 13.2 & $(3.45)$ & 13.5 & (3.28) & 11.2 & $(2.61)$ & $-17 \%$ \\
\hline AFDC generosity (15 year lag) & 7270 & $(3009)$ & 7975 & $(2858)$ & 6093 & $(2403)$ & $-24 \%$ \\
\hline Prisoners per 1000 population & 3.33 & $(1.56)$ & 2.65 & $(1.03)$ & 4.52 & $(1.67)$ & $71 \%$ \\
\hline Police per 1000 population & 2.98 & $(0.69)$ & 2.79 & $(0.64)$ & 3.30 & $(0.74)$ & $18 \%$ \\
\hline Beer consumption per capita (gallons) & 22.70 & $(3.36)$ & 24.04 & $(3.22)$ & 21.76 & $(3.32)$ & $-9 \%$ \\
\hline Share of population age 15 to 29 & 0.22 & $(0.02)$ & 0.23 & $(0.01)$ & 0.21 & $(0.01)$ & $-11 \%$ \\
\hline $\begin{array}{l}\text { Effective teen pregnancy rate } \\
\text { (for violent crime) }\end{array}$ & 0.12 & $(0.03)$ & 0.12 & $(0.03)$ & 0.11 & $(0.02)$ & $-3 \%$ \\
\hline
\end{tabular}

Notes. Means are calculated across 51 states (including the District of Columbia) for the years indicated and are weighted by state population. Standard errors are in parentheses. Variables are defined in the text and Data Appendix. 
Table 2. Regression of Air Lead on Gasoline Lead (grams per gallon).

Coefficient on

Gasoline Lead (grams per gallon)
R-squared

0.28

$(0.023)$

Weighted by state population

0.433 **

0.36

$(0.050)$

With state f.e. and year f.e.

0.293 **

0.58

$(0.145)$

With fixed effects and weighted

0.465 **

0.66

$(0.203)$

Exclude NY

0.337 **

(0.024)

Exclude CA

0.325 **

(0.020)

Exclude NY, CA, DC

0.326 **

$(0.021)$

With fixed effects and weighted, exclude NY, CA, DC

0.216 *

$(0.132)$

Exclude 11 states $^{a}$

0.372 **

(0.023)

Including population density

\footnotetext{
${ }^{a}$ This specification excludes eleven states that have implausibly low air lead measures in the 1960s. These states are AK, AR, ID, KS, ME, MT, OR, RI, SC, SD, VA, VT, WY.

Notes. Coefficients are from the OLS regression of air lead $\left(\mu \mathrm{g} / \mathrm{m}^{3}\right)$ on gasoline lead (grams per gallon). The baseline specification includes state-year level observations for 51 states for the years 1965 to 1985 . Observations are not weighted, except where indicated, in which case they are weighted by state population. Each row is modified as indicated on the left of the table. Standard errors are shown in parentheses and are Huber-White robust and corrected for serial correlation in a short panel by clustering on state. Significance is indicated by ${ }^{* *}$ for $p$-values below 0.05 and * for $p$-values below 0.10 .
} 


\section{Table 3. Regression of Blood Lead on Gasoline Lead (grams per gallon).}

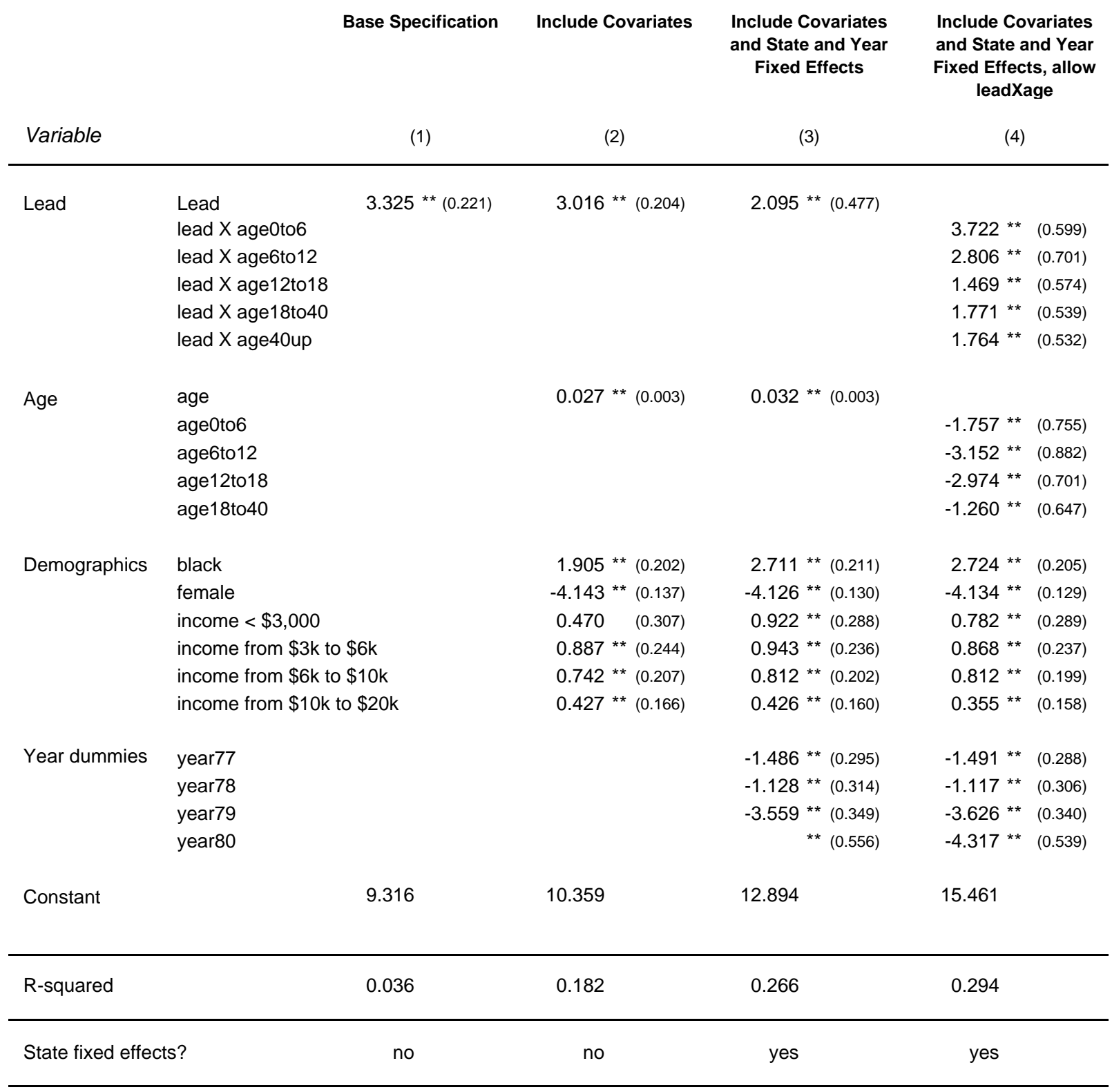

Notes. Coefficients are from the OLS regression of blood lead on gasoline lead (grams per gallon). Individual data on blood lead and demographics is from the NHANES II. The exact date on which the blood lead sample was taken is known. Gasoline lead data is available monthly at the state level and is calculated as described in the text and the Data Appendix. This regression is on the full sample of 9,372 people of all ages (resident in one of the 51 states or the District of Columbia) for the years 1976 to 1980, and is weighted by NHANES II data weights. Standard errors are Huber-White robust and are shown in parentheses. Significance is indicated by ** for $p$-values below 0.05 and * for $p$-values below 0.10 . 
Table 4. Regression of Blood Lead on Various Lead Measures.

\begin{tabular}{lcccc} 
& $\begin{array}{c}\text { Base } \\
\text { Specification }\end{array}$ & $\begin{array}{c}\text { Include } \\
\text { Covariates }\end{array}$ & $\begin{array}{c}\text { Include } \\
\text { Covariates and } \\
\text { State and Year } \\
\text { Fixed Effects }\end{array}$ & $\begin{array}{c}\text { Include } \\
\text { Covariates and } \\
\text { State and Year } \\
\text { Fixed Effects, } \\
\text { drop 3 states }\end{array}$ \\
\hline Gasoline Lead (grams per gallon) & $0.402 * *$ & $0.350 * *$ & $0.546 * *$ & $0.844 * *$ \\
Per-capita Lead & $(0.040)$ & $(0.036)$ & $(0.101)$ & $(0.118)$ \\
Air Lead & $0.124 * *$ & $0.101 * *$ & $0.302 * *$ & $0.379 * *$ \\
IV Air Lead & $(0.029)$ & $(0.026)$ & $(0.086)$ & $(0.106)$ \\
& $0.114 * *$ & $0.128 * *$ & 0.006 & $0.082 *$ \\
& $(0.013)$ & $(0.012)$ & $(0.034)$ & $(0.048)$ \\
\hline
\end{tabular}

Notes. Coefficients are from the OLS regression of blood lead on the lead measure indicated at the left. Elasticities over the sample period 1976-1980 are shown. Column 1 includes no additional covariates. Column 2 includes age, black dummy, gender dummy, and income category dummies. Column 3 controls for these covariates and includes state and year fixed effects. Column 4 is the same as column 3 but excludes individuals living in New York, California, and the District of Columbia. Individual data on blood lead and demographics is from the NHANES II. Lead exposure measures are calculated as described in the text and Data Appendix. This regression is on the sample of 2,322 people under the age of 6 (resident in one of the 51 states or the District of Columbia) for the years 1976 to 1980, and is weighted by NHANES II data weights for blood lead. Standard errors are Huber-White robust and are shown in parentheses. Significance is indicated by ** for $p$-values below 0.05 and * for $p$-values below 0.10 . 
Table 5. Crime Trends in High Lead States vs. Low Lead States, 1972-2002, for Violent Crime, Property Crime, and Murder.

\begin{tabular}{|c|c|c|c|c|c|c|c|c|}
\hline \multirow[b]{2}{*}{ Crime } & & \multicolumn{7}{|c|}{ Percent change in crime in the time period } \\
\hline & & $72-77$ & $77-82$ & $82-87$ & $87-92$ & $92-97$ & $97-02$ & $85-02$ \\
\hline \multirow[t]{4}{*}{ Violent } & high lead & 16.6 & 20.8 & 7.9 & 19.3 & -24.5 & $\overline{-21.6}$ & -26.8 \\
\hline & low lead & 16.9 & 13.0 & 0.1 & 26.3 & -10.0 & -15.3 & 0.9 \\
\hline & difference $=$ high - low & -0.3 & 7.9 & 7.8 & -7.0 & -14.5 & -6.3 & -27.7 \\
\hline & standard error & $(5.7)$ & $(5.2)$ & $(4.4)$ & $(4.8)$ & $(6.5)$ & $(5.7)$ & $(10.2)$ \\
\hline \multirow[t]{4}{*}{ Property } & high lead & 25.1 & 8.6 & -3.5 & -1.8 & -18.4 & -20.6 & -40.9 \\
\hline & low lead & 28.8 & 10.2 & -4.6 & 3.3 & -6.0 & -17.8 & -20.5 \\
\hline & difference $=$ high - low & -3.7 & -1.6 & 1.2 & -5.1 & -12.4 & -2.9 & -20.4 \\
\hline & standard error & $(4.9)$ & $(2.9)$ & $(4.6)$ & $(3.2)$ & $(5.1)$ & $(3.7)$ & $(8.5)$ \\
\hline \multirow[t]{4}{*}{ Murder } & high lead & -0.7 & 5.7 & -9.4 & 7.8 & -35.9 & $\overline{-18.2}$ & -46.3 \\
\hline & low lead & 5.9 & -6.8 & -8.3 & 14.7 & -14.7 & -29.3 & -29.3 \\
\hline & difference $=$ high - low & -6.6 & 12.5 & -1.1 & -6.9 & -21.2 & 11.1 & -17.0 \\
\hline & standard error & $(9.5)$ & $(5.7)$ & (7.4) & (8.3) & $(9.9)$ & (5.0) & (11.3) \\
\hline
\end{tabular}

Notes. States are divided into high lead and low lead categories by the size of the change in lead exposure over the period 1970 to 1980. High lead states are those whose change in lead exposure is in the top third of changes, low lead states are those whose change in lead exposure is in the bottom third of changes. Change in crime in the time period is the mean over that group of states of the percentage change in the per capita crime rate. Means are weighted by state population. Standard error is the standard error of the difference in the percent changes. 
Table 6. Panel Data Estimates of the Relationship Between Childhood Lead Exposure and Crime.

\begin{tabular}{|c|c|c|c|c|c|c|c|c|c|}
\hline \multirow[b]{2}{*}{ Variable } & \multicolumn{3}{|c|}{ Violent Crime } & \multicolumn{3}{|c|}{ Property Crime } & \multicolumn{3}{|c|}{ Murder } \\
\hline & (1) & $(2)$ & (3) & (4) & (5) & (6) & (7) & (8) & (9) \\
\hline Lead (grams per gallon) & $\begin{array}{l}0.976 \text { * } \\
(0.542)\end{array}$ & $\begin{array}{l}0.888 \text { ** } \\
(0.449)\end{array}$ & $\begin{array}{l}0.785 \text { ** } \\
(0.403)\end{array}$ & $\begin{array}{l}0.427 \\
(0.368)\end{array}$ & $\begin{array}{r}-0.046 \\
(0.304)\end{array}$ & $\begin{array}{r}-0.078 \\
(0.281)\end{array}$ & $\begin{array}{l}1.084 \\
(0.656)\end{array}$ & $\begin{array}{l}0.492 \\
(0.650)\end{array}$ & $\begin{array}{l}0.369 \\
(0.596)\end{array}$ \\
\hline Abortion & & & $\begin{array}{l}-0.224 \text { ** } \\
(0.057)\end{array}$ & & & $\begin{array}{l}-0.144 \text { ** } \\
(0.056)\end{array}$ & & & $\begin{array}{l}-0.232 \text { ** } \\
(0.067)\end{array}$ \\
\hline State unemployment rate & & $\begin{array}{r}-0.023 \\
(1.057)\end{array}$ & $\begin{array}{l}0.702 \\
(0.839)\end{array}$ & & $\begin{array}{l}2.329 * * \\
(0.880)\end{array}$ & $\begin{array}{l}2.878 \text { ** } \\
(0.819)\end{array}$ & & $\begin{array}{l}2.086 \text { ** } \\
(1.314)\end{array}$ & $\begin{array}{l}2.845 \text { ** } \\
(1.221)\end{array}$ \\
\hline Log income per capita & & $\begin{array}{l}-0.547 \\
(0.350)\end{array}$ & $\begin{array}{l}-0.073 \\
(0.371)\end{array}$ & & $\begin{array}{l}-0.434 \\
(0.277)\end{array}$ & $\begin{array}{r}-0.171 \\
(0.285)\end{array}$ & & $\begin{array}{r}-0.092 \\
(0.387)\end{array}$ & $\begin{array}{l}0.440 \\
(0.491)\end{array}$ \\
\hline Poverty rate & & $\begin{array}{l}-0.007 \\
(0.005)\end{array}$ & $\begin{array}{l}-0.003 \\
(0.004)\end{array}$ & & $\begin{array}{l}-0.009 \text { ** } \\
(0.004)\end{array}$ & $\begin{array}{l}-0.008 \text { ** } \\
(0.004)\end{array}$ & & $\begin{array}{l}-0.016 \text { ** } \\
(0.008)\end{array}$ & $\begin{array}{c}-0.011 \text { * } \\
(0.007)\end{array}$ \\
\hline AFDC generosity (15 yr lag) & & $\begin{array}{l}0.013 \\
(0.013)\end{array}$ & $\begin{array}{l}0.008 \\
(0.011)\end{array}$ & & $\begin{array}{l}0.005 \\
(0.012)\end{array}$ & $\begin{array}{l}0.003 \\
(0.012)\end{array}$ & & $\begin{array}{l}0.010 \\
(0.024)\end{array}$ & $\begin{array}{l}0.005 \\
(0.021)\end{array}$ \\
\hline Teen pregnancy rate (effective) & & $\begin{array}{l}2.276 \\
(3.961)\end{array}$ & $\begin{array}{l}0.263 \\
(3.471)\end{array}$ & & $\begin{array}{l}0.444 \\
(2.888)\end{array}$ & $\begin{array}{r}-0.511 \\
(2.597)\end{array}$ & & $\begin{array}{l}6.376 \\
(5.364)\end{array}$ & $\begin{array}{l}3.734 \\
(5.004)\end{array}$ \\
\hline Log prisoners per capita ( 1 yr lag) & & $\begin{array}{l}0.119 \\
(0.110)\end{array}$ & $\begin{array}{l}0.061 \\
(0.092)\end{array}$ & & $\begin{array}{r}-0.138 \\
(0.111)\end{array}$ & $\begin{array}{r}-0.150 \\
(0.108)\end{array}$ & & $\begin{array}{r}-0.133 \\
(0.159)\end{array}$ & $\begin{array}{r}-0.214 \\
(0.133)\end{array}$ \\
\hline Log police per capita (1 yr lag) & & $\begin{array}{l}-0.221 \text { ** } \\
(0.117)\end{array}$ & $\begin{array}{l}-0.181 \text { * } \\
(0.110)\end{array}$ & & $\begin{array}{l}-0.214 \\
(0.152)\end{array}$ & $\begin{array}{r}-0.189 \\
(0.150)\end{array}$ & & $\begin{array}{l}-0.424 \text { ** } \\
(0.179)\end{array}$ & $\begin{array}{l}-0.383 \text { ** } \\
(0.173)\end{array}$ \\
\hline Shall-issue concealed weapons law & & $\begin{array}{l}0.060 \text { ** } \\
(0.030)\end{array}$ & $\begin{array}{l}0.041 \text { * } \\
(0.026)\end{array}$ & & $\begin{array}{l}0.066 \text { ** } \\
(0.028)\end{array}$ & $\begin{array}{l}0.058 \text { ** } \\
(0.026)\end{array}$ & & $\begin{array}{r}-0.020 \\
(0.054)\end{array}$ & $\begin{array}{r}-0.044 \\
(0.050)\end{array}$ \\
\hline Beer consumption per capita & & $\begin{array}{l}0.043 \text { ** } \\
(0.013)\end{array}$ & $\begin{array}{l}0.020 \text { ** } \\
(0.011)\end{array}$ & & $\begin{array}{l}0.059 \text { ** } \\
(0.011)\end{array}$ & $\begin{array}{l}0.047 \text { ** } \\
(0.012)\end{array}$ & & $\begin{array}{l}0.031 \text { * } \\
(0.019)\end{array}$ & $\begin{array}{l}0.004 \\
(0.020)\end{array}$ \\
\hline Share of population age 15 to 29 & & $\begin{array}{l}1.141 \\
(1.855)\end{array}$ & $\begin{array}{r}-1.285 \\
(1.737)\end{array}$ & & $\begin{array}{l}1.310 \\
(1.291)\end{array}$ & $\begin{array}{r}-0.121 \\
(1.151)\end{array}$ & & $\begin{array}{l}2.384 \\
(2.389)\end{array}$ & $\begin{array}{r}-0.303 \\
(2.287)\end{array}$ \\
\hline R-squared & 0.95 & 0.96 & 0.96 & 0.94 & 0.96 & 0.96 & 0.94 & 0.96 & 0.96 \\
\hline
\end{tabular}

Notes. The dependent variable is the natural log of the per capita crime rate shown at the top of the column. The independent variable of interest is effective gasoline lead exposure (grams per gallon) in the first three years of life, corrected for inter-state migration. In order to represent the average elasticity over the sample period, coefficients and standard errors shown for effective lead exposure have been multiplied by the mean of the effective lead exposure variable over the sample period (see Table $1,1.27$ grams per gallon.) Coefficients and standard errors for effective abortion exposure have been similarly adjusted. AFDC generosity has been rescaled by 1000 . The data include annual state-level observations for 51 states (including DC) for the years 1985 to 2002 (918 observations). State and year fixed effects are included in all specifications. Variables are summarized in Table 1 and defined in the Data Appendix. Standard errors are shown in parentheses and are Huber-White robust and corrected for serial correlation in a short panel by clustering on state. Observations are weighted by state population. Significance is indicated by ** for $p$-values below 0.05 and * for $p$-values below 0.10 . 


\section{Table 7. Sensitivity Analysis for Panel Data Estimates of the Relationship Between Childhood Lead Exposure and Crime.}

\begin{tabular}{|c|c|c|c|}
\hline & Violent Crime & Property Crime & Murder \\
\hline Baseline & $\begin{array}{l}0.785 * * \\
(0.403)\end{array}$ & $\begin{array}{r}-0.078 \\
(0.281)\end{array}$ & $\begin{array}{l}0.369 \\
(0.596)\end{array}$ \\
\hline Exclude New York & $\begin{array}{l}0.963 * * \\
(0.377)\end{array}$ & $\begin{array}{r}-0.103 \\
(0.244)\end{array}$ & $\begin{array}{l}0.684 \\
(0.560)\end{array}$ \\
\hline Exclude California & $\begin{array}{l}0.930 \text { ** } \\
(0.416)\end{array}$ & $\begin{array}{l}0.086 \\
(0.291)\end{array}$ & $\begin{array}{l}0.749 \\
(0.555)\end{array}$ \\
\hline Exclude the District of Columbia & $\begin{array}{l}0.826 \text { ** } \\
(0.383)\end{array}$ & $\begin{array}{r}-0.049 \\
(0.280)\end{array}$ & $\begin{array}{l}0.394 \\
(0.567)\end{array}$ \\
\hline Exclude NY, CA, DC & $\begin{array}{l}1.146 \text { ** } \\
(0.325)\end{array}$ & $\begin{array}{l}0.053 \\
(0.208)\end{array}$ & $\begin{array}{l}1.075 \text { ** } \\
(0.393)\end{array}$ \\
\hline Include state-specific trends & $\begin{array}{l}0.241 \\
(0.754)\end{array}$ & $\begin{array}{l}0.096 \\
(0.174)\end{array}$ & $\begin{array}{l}0.534 \\
(0.634)\end{array}$ \\
\hline Include region-year interactions & $\begin{array}{l}1.813 * * \\
(0.466)\end{array}$ & $\begin{array}{l}0.637 \\
(0.501)\end{array}$ & $\begin{array}{l}1.887 * * \\
(0.740)\end{array}$ \\
\hline Unweighted & $\begin{array}{l}0.969 * * \\
(0.440)\end{array}$ & $\begin{array}{r}-0.328 \\
(0.216)\end{array}$ & $\begin{array}{l}0.745 \\
(0.468)\end{array}$ \\
\hline Unweighted, exclude NY, CA, DC & $\begin{array}{l}1.081 * * \\
(0.406)\end{array}$ & $\begin{array}{r}-0.268 \\
(0.196)\end{array}$ & $\begin{array}{l}0.938 * * \\
(0.403)\end{array}$ \\
\hline Not cross-state migration corrected & $\begin{array}{l}0.447 \\
(0.312)\end{array}$ & $\begin{array}{r}-0.147 \\
(0.196)\end{array}$ & $\begin{array}{l}0.170 \\
(0.480)\end{array}$ \\
\hline $\begin{array}{c}\text { Not cross-state migration corrected } \\
\text { exclude NY, CA, DC }\end{array}$ & $\begin{array}{l}0.874 \\
(0.273)\end{array}$ & $\begin{array}{l}0.044 \\
(0.165)\end{array}$ & $\begin{array}{l}0.853 * * \\
(0.342)\end{array}$ \\
\hline Use Log of lead exposure & $\begin{array}{l}0.786 \text { ** } \\
(0.323)\end{array}$ & $\begin{array}{l}0.638 \text { ** } \\
(0.295)\end{array}$ & $\begin{array}{r}-0.070 \\
(0.416)\end{array}$ \\
\hline $\begin{array}{l}\text { Use Log of lead exposure, } \\
\text { exclude NY, CA, DC }\end{array}$ & $\begin{array}{l}0.898 \text { ** } \\
(0.334)\end{array}$ & $\begin{array}{l}0.254 \\
(0.296)\end{array}$ & $\begin{array}{l}0.310 \\
(0.402)\end{array}$ \\
\hline
\end{tabular}

Notes. Coefficients shown are average elasticities of crime with respect to lead over the sample period. The baseline specification is identical to that shown in Table 6, Columns 3, 6, and 9. It includes all statelevel controls and state and year fixed effects. Each additional row is modified as indicated on the left of the table. Standard errors are shown in parentheses and are Huber-White robust and corrected for serial correlation in a short panel by clustering on state. Observations are weighted by state population. Significance is indicated by ** for $p$-values below 0.05 and * for p-values below 0.10 . 
Table 8. Violent Crime Results Using Alternate Lead Measures.

\begin{tabular}{|c|c|c|c|c|}
\hline & \multicolumn{2}{|c|}{ Gasoline Lead Measures } & \multicolumn{2}{|c|}{ Air Lead Measures } \\
\hline & $\begin{array}{c}\text { Grams Per } \\
\text { Gallon }\end{array}$ & $\begin{array}{l}\text { Per-Capita } \\
\text { Lead }\end{array}$ & Air Lead & $\begin{array}{l}\text { IV (gpg } \\
\text { instr for air) }\end{array}$ \\
\hline Linear & $\begin{array}{l}0.785 \text { ** } \\
(0.403)\end{array}$ & $\begin{array}{l}0.127 \\
(0.444)\end{array}$ & $\begin{array}{l}0.210 \text { ** } \\
(0.086)\end{array}$ & $\begin{array}{l}0.980 \text { ** } \\
(0.474)\end{array}$ \\
\hline Linear, Exclude NY & $\begin{array}{l}0.963 \text { ** } \\
(0.377)\end{array}$ & $\begin{array}{l}0.740 \text { ** } \\
(0.317)\end{array}$ & $\begin{array}{l}0.193 \text { ** } \\
(0.092)\end{array}$ & $\begin{array}{l}1.192 \text { ** } \\
(0.437)\end{array}$ \\
\hline Linear, Exclude NY, CA, DC & $\begin{array}{l}1.146 \text { ** } \\
(0.325)\end{array}$ & $\begin{array}{l}0.788 \text { ** } \\
(0.293)\end{array}$ & $\begin{array}{l}0.078 \\
(0.116)\end{array}$ & $\begin{array}{l}1.374 \text { ** } \\
(0.389)\end{array}$ \\
\hline Log & $\begin{array}{l}0.786 \text { ** } \\
(0.323)\end{array}$ & $\begin{array}{l}0.758 \text { ** } \\
(0.299)\end{array}$ & $\begin{array}{l}0.159 \\
(0.124)\end{array}$ & $\begin{array}{l}1.075 \text { ** } \\
(0.429)\end{array}$ \\
\hline Log, Exclude NY & $\begin{array}{l}1.027 \text { ** } \\
(0.318)\end{array}$ & $\begin{array}{l}1.028 \text { ** } \\
(0.292)\end{array}$ & $\begin{array}{l}0.125 \\
(0.127)\end{array}$ & $\begin{array}{l}1.378 \text { ** } \\
(0.397)\end{array}$ \\
\hline Log, Exclude NY, CA, DC & $\begin{array}{l}0.898 \text { ** } \\
(0.334)\end{array}$ & $\begin{array}{l}0.957 \text { ** } \\
(0.326)\end{array}$ & $\begin{array}{l}0.042 \\
(0.125)\end{array}$ & $\begin{array}{l}1.300 \text { ** } \\
(0.409)\end{array}$ \\
\hline
\end{tabular}

Notes. Coefficients shown are average elasticities of violent crime with respect to lead over the sample period. The baseline specification is identical to that shown in Column 3 of Table 6 . It includes all state-level controls and state and year fixed effects. Each additional row is modified as indicated on the left of the table. Each column shows results for the lead measure indicated at the top of the column. The lead measures are migration-corrected effective lead exposures, calculated as described in the text and Data Appendix. For the IV measure, the first stage regresses air lead on gasoline lead (grams per gallon) using available data in the 1965 to 1985 period; the estimated equation is used to predict air lead out of sample for the period 1950 to 1990; the effective lead measure is calculated following Equation 6. Standard errors are shown in parentheses and are Huber-White robust and corrected for serial correlation in a short panel by clustering on state. Observations are weighted by state population. Significance is indicated by ** for $p$-values below 0.05 and * for p-values below 0.10 . 
Appendix Table 1. Lead Exposure by State, 1975-1985.

\begin{tabular}{|c|c|c|c|c|c|c|c|c|c|c|}
\hline \multicolumn{2}{|c|}{ State } & \multicolumn{3}{|c|}{$\begin{array}{l}\text { Gasoline Lead } \\
\text { (grams per gallon) }\end{array}$} & \multicolumn{3}{|c|}{$\begin{array}{l}\text { Per-capita Lead } \\
\text { (kilograms per person) }\end{array}$} & \multicolumn{3}{|l|}{$\begin{array}{l}\text { Air Lead } \\
\left(\mu g / m^{3}\right)\end{array}$} \\
\hline & & 1975 & 1980 & 1985 & 1975 & 1980 & 1985 & 1975 & 1980 & 1985 \\
\hline$A L$ & Alabama & 1.91 & 0.88 & 0.20 & 1.09 & 0.51 & 0.11 & 0.87 & 0.51 & 0.31 \\
\hline AK & Alaska & 1.39 & 0.65 & 0.23 & 0.80 & 0.34 & 0.14 & 1.18 & 0.67 & 0.34 \\
\hline$A Z$ & Arizona & 1.68 & 0.73 & 0.20 & 0.97 & 0.41 & 0.11 & 0.96 & 0.44 & 0.23 \\
\hline AR & Arkansas & 2.05 & 0.95 & 0.29 & 1.24 & 0.56 & 0.18 & 0.83 & 0.41 & 0.20 \\
\hline CA & California & 1.41 & 0.49 & 0.22 & 0.71 & 0.25 & 0.11 & 1.62 & 0.64 & 0.17 \\
\hline $\mathrm{CO}$ & Colorado & 1.71 & 0.74 & 0.16 & 0.91 & 0.40 & 0.09 & 1.30 & 0.46 & 0.20 \\
\hline CT & Connecticut & 1.65 & 0.68 & 0.18 & 0.74 & 0.30 & 0.08 & 1.00 & 0.57 & 0.17 \\
\hline DE & Delaware & 1.67 & 0.69 & 0.07 & 0.88 & 0.37 & 0.04 & 0.70 & 0.45 & 0.14 \\
\hline DC & Dist. of Columbia & 1.51 & 0.56 & 0.14 & 0.51 & 0.14 & 0.04 & 0.98 & 0.68 & 0.16 \\
\hline $\mathrm{FL}$ & Florida & 1.92 & 0.75 & 0.15 & 1.02 & 0.41 & 0.08 & 0.85 & 0.35 & 0.19 \\
\hline GA & Georgia & 1.90 & 0.82 & 0.17 & 1.15 & 0.50 & 0.11 & 0.83 & 0.45 & 0.13 \\
\hline $\mathrm{HI}$ & Hawaii & 1.61 & 0.55 & 0.47 & 0.54 & 0.19 & 0.16 & 0.65 & 0.24 & 0.06 \\
\hline ID & Idaho & 1.46 & 0.78 & 0.33 & 0.87 & 0.42 & 0.18 & 1.42 & 0.50 & 0.25 \\
\hline IL & Illinois & 1.51 & 0.67 & 0.17 & 0.68 & 0.30 & 0.08 & 1.69 & 0.37 & 0.16 \\
\hline IN & Indiana & 1.77 & 0.84 & 0.24 & 1.00 & 0.48 & 0.14 & 0.87 & 0.37 & 0.33 \\
\hline IA & lowa & 1.64 & 0.84 & 0.25 & 0.95 & 0.43 & 0.14 & 0.68 & 0.28 & 0.13 \\
\hline KS & Kansas & 1.72 & 0.79 & 0.25 & 1.04 & 0.49 & 0.15 & 0.40 & 0.26 & 0.09 \\
\hline $\mathrm{KY}$ & Kentucky & 1.81 & 0.89 & 0.26 & 0.98 & 0.48 & 0.14 & 0.81 & 0.39 & 0.19 \\
\hline LA & Louisiana & 1.91 & 0.75 & 0.17 & 0.98 & 0.40 & 0.08 & 0.83 & 0.39 & 0.15 \\
\hline ME & Maine & 1.76 & 0.94 & 0.27 & 0.94 & 0.47 & 0.15 & 0.49 & 0.31 & 0.15 \\
\hline MD & Maryland & 1.56 & 0.63 & 0.15 & 0.73 & 0.31 & 0.07 & 0.98 & 0.42 & 0.15 \\
\hline MA & Massachusetts & 1.69 & 0.80 & 0.18 & 0.71 & 0.34 & 0.08 & 0.86 & 0.48 & 0.20 \\
\hline MI & Michigan & 1.46 & 0.69 & 0.16 & 0.73 & 0.32 & 0.08 & 0.87 & 0.21 & 0.11 \\
\hline $\mathrm{MN}$ & Minnesota & 1.69 & 0.70 & 0.16 & 0.90 & 0.38 & 0.08 & 0.62 & 0.61 & 0.15 \\
\hline MS & Mississippi & 1.92 & 0.91 & 0.28 & 1.05 & 0.50 & 0.16 & 0.57 & 0.29 & 0.12 \\
\hline MO & Missouri & 1.84 & 0.88 & 0.26 & 1.04 & 0.51 & 0.16 & 0.78 & 0.55 & 0.26 \\
\hline MT & Montana & 1.43 & 0.79 & 0.27 & 0.93 & 0.53 & 0.17 & 0.30 & 0.26 & 0.95 \\
\hline NE & Nebraska & 1.71 & 0.81 & 0.19 & 1.09 & 0.51 & 0.12 & 0.61 & 0.31 & 0.30 \\
\hline NV & Nevada & 1.66 & 0.70 & 0.26 & 1.21 & 0.48 & 0.16 & 1.72 & 0.49 & 0.20 \\
\hline $\mathrm{NH}$ & New Hampshire & 1.69 & 0.77 & 0.18 & 0.83 & 0.35 & 0.09 & 0.44 & 0.14 & 0.11 \\
\hline NJ & New Jersey & 1.56 & 0.64 & 0.17 & 0.73 & 0.30 & 0.08 & 1.02 & 0.42 & 0.32 \\
\hline NM & New Mexico & 1.67 & 0.72 & 0.17 & 1.14 & 0.49 & 0.10 & 0.33 & 0.75 & 0.26 \\
\hline NY & New York & 1.57 & 0.67 & 0.19 & 0.49 & 0.21 & 0.07 & 0.86 & 0.30 & 0.23 \\
\hline NC & North Carolina & 1.99 & 0.88 & 0.21 & 1.09 & 0.48 & 0.12 & 0.93 & 0.35 & 0.13 \\
\hline ND & North Dakota & 1.71 & 0.80 & 0.23 & 0.99 & 0.50 & 0.16 & 0.66 & 0.14 & 0.10 \\
\hline $\mathrm{OH}$ & Ohio & 1.65 & 0.69 & 0.18 & 0.83 & 0.35 & 0.09 & 0.75 & 0.44 & 0.17 \\
\hline OK & Oklahoma & 1.91 & 0.72 & 0.27 & 1.23 & 0.47 & 0.18 & 0.56 & 0.26 & 0.11 \\
\hline OR & Oregon & 1.57 & 0.69 & 0.40 & 0.92 & 0.34 & 0.19 & 0.77 & 0.41 & 0.16 \\
\hline PA & Pennsylvania & 1.63 & 0.69 & 0.25 & 0.69 & 0.31 & 0.11 & 0.83 & 0.36 & 0.27 \\
\hline RI & Rhode Island & 1.65 & 0.70 & 0.18 & 0.70 & 0.29 & 0.07 & 0.91 & 0.55 & 0.21 \\
\hline SC & South Carolina & 1.98 & 0.85 & 0.21 & 1.11 & 0.48 & 0.12 & 0.81 & 0.36 & 0.12 \\
\hline SD & South Dakota & 1.72 & 0.84 & 0.24 & 1.10 & 0.52 & 0.16 & 0.33 & 0.19 & 0.01 \\
\hline $\mathrm{TN}$ & Tennessee & 1.94 & 0.85 & 0.22 & 1.14 & 0.50 & 0.13 & 1.31 & 0.43 & 0.35 \\
\hline $\mathrm{TX}$ & Texas & 2.10 & 0.86 & 0.21 & 1.35 & 0.54 & 0.14 & 0.53 & 0.27 & 0.18 \\
\hline UT & Utah & 1.69 & 0.75 & 0.26 & 0.95 & 0.39 & 0.13 & 0.98 & 0.16 & 0.27 \\
\hline VT & Vermont & 1.72 & 0.83 & 0.22 & 0.86 & 0.38 & 0.12 & 0.68 & 0.03 & 0.03 \\
\hline VA & Virginia & 1.60 & 0.73 & 0.20 & 0.85 & 0.39 & 0.11 & 0.45 & 0.34 & 0.10 \\
\hline WA & Washington & 1.57 & 0.68 & 0.28 & 0.79 & 0.34 & 0.14 & 0.74 & 0.42 & 0.28 \\
\hline WV & West Virginia & 1.60 & 0.72 & 0.19 & 0.78 & 0.35 & 0.09 & 0.87 & 0.27 & 0.10 \\
\hline WI & Wisconsin & 1.56 & 0.76 & 0.20 & 0.78 & 0.39 & 0.10 & 0.80 & 0.30 & 0.17 \\
\hline \multirow[t]{2}{*}{ WY } & Wyoming & 1.41 & 0.71 & 0.28 & 1.40 & 0.66 & 0.24 & 0.21 & 0.02 & 0.01 \\
\hline & United States & 1.68 & 0.72 & 0.21 & 0.86 & 0.37 & 0.11 & 0.93 & 0.40 & 0.19 \\
\hline
\end{tabular}

Notes. Lead measures are calculated as described in the text and Data Appendix. 


\section{Appendix Table 2. States with high or low values of populat population density, gasoline, and lead variables. (1975 I}

\begin{tabular}{|c|c|}
\hline \multicolumn{2}{|c|}{ Population Top Five: } \\
\hline 1. $\mathrm{CA}$ & $21,537,849$ \\
\hline NY & $18,003,485$ \\
\hline 3. $\mathrm{TX}$ & $12,568,843$ \\
\hline 4. $\mathrm{PA}$ & $11,906,095$ \\
\hline 5. IL & $11,291,743$ \\
\hline Median & $2,880,847$ \\
\hline \multicolumn{2}{|c|}{ Per-Capita Lead Bottom Five. } \\
\hline 1. NY & 0.49 \\
\hline DC & 0.51 \\
\hline $\mathrm{HI}$ & 0.54 \\
\hline 4. & 0.68 \\
\hline PA & 0.69 \\
\hline Median & 0.93 \\
\hline \multicolumn{2}{|c|}{ Population Density Top Five: } \\
\hline NY & 47,307 \\
\hline DC & 31,107 \\
\hline $\mathrm{NJ}$ & 17,037 \\
\hline 4. $\mathrm{CO}$ & 14,794 \\
\hline 5. IL & 14,722 \\
\hline Median & 4,395 \\
\hline
\end{tabular}

Notes. Values are for each state in 1975, as described in the Data Appendix. Population is number of people in the state. Population density is the average density within which people live, where density is measured as people per square mile. Per-capita lead is measured in kilograms of lead per person per year. 


\section{Appendix Table 3. Spline for Violent Crime.}

\begin{tabular}{|c|c|c|c|c|}
\hline Sample & & $\begin{array}{l}\text { Grams Per } \\
\text { Gallon }\end{array}$ & $\begin{array}{l}\text { Per-Capita } \\
\text { Lead }\end{array}$ & $\begin{array}{l}\text { IV (gpg instr } \\
\text { for air) }\end{array}$ \\
\hline \multirow[t]{4}{*}{ Full Sample } & Lead in 1st quartile & $\begin{array}{l}0.775 \text { ** } \\
(0.337)\end{array}$ & $\begin{array}{l}0.734 \text { ** } \\
(0.238)\end{array}$ & $\begin{array}{l}1.048 \text { ** } \\
(0.463)\end{array}$ \\
\hline & Lead in 2nd quartile & $\begin{array}{l}0.710 \text { ** } \\
(0.441)\end{array}$ & $\begin{array}{l}0.176 \\
(0.453)\end{array}$ & $\begin{array}{l}0.896 \text { ** } \\
(0.544)\end{array}$ \\
\hline & Lead in 3rd quartile & $\begin{array}{l}1.277 \text { ** } \\
(0.632)\end{array}$ & $\begin{array}{l}0.789 * * \\
(0.425)\end{array}$ & $\begin{array}{l}1.579 \text { ** } \\
(0.739)\end{array}$ \\
\hline & Lead in 4 th quartile & $\begin{array}{l}0.975 \text { ** } \\
(0.481)\end{array}$ & $\begin{array}{l}0.820 \text { ** } \\
(0.434)\end{array}$ & $\begin{array}{l}1.081 \text { ** } \\
(0.554)\end{array}$ \\
\hline \multirow[t]{4}{*}{ Drop NY } & Lead in 1st quartile & $\begin{array}{l}1.007 \text { ** } \\
(0.309)\end{array}$ & $\begin{array}{l}0.955 \text { ** } \\
(0.244)\end{array}$ & $\begin{array}{l}1.345 \text { ** } \\
(0.422)\end{array}$ \\
\hline & Lead in 2nd quartile & $\begin{array}{l}0.890 \text { ** } \\
(0.377)\end{array}$ & $\begin{array}{l}0.977 \text { ** } \\
(0.313)\end{array}$ & $\begin{array}{l}1.102 \text { ** } \\
(0.463)\end{array}$ \\
\hline & Lead in 3rd quartile & $\begin{array}{l}1.626 \text { ** } \\
(0.559)\end{array}$ & $\begin{array}{l}1.139 * * \\
(0.365)\end{array}$ & $\begin{array}{l}1.994 \text { ** } \\
(0.637)\end{array}$ \\
\hline & Lead in 4th quartile & $\begin{array}{l}1.194 \text { ** } \\
(0.441)\end{array}$ & $\begin{array}{l}1.302 \text { ** } \\
(0.372)\end{array}$ & $\begin{array}{l}1.305 \text { ** } \\
(0.518)\end{array}$ \\
\hline \multirow[t]{4}{*}{ Drop NY, CA, DC } & Lead in 1st quartile & $\begin{array}{l}0.786 \text { ** } \\
(0.334)\end{array}$ & $\begin{array}{l}0.831 \text { ** } \\
(0.246)\end{array}$ & $\begin{array}{l}1.064 \text { ** } \\
(0.453)\end{array}$ \\
\hline & Lead in 2 nd quartile & $\begin{array}{l}1.052 \text { ** } \\
(0.427)\end{array}$ & $\begin{array}{l}0.955 * * \\
(0.310)\end{array}$ & $\begin{array}{l}1.277^{* *} \\
(0.518)\end{array}$ \\
\hline & Lead in 3rd quartile & $\begin{array}{l}1.931 \text { ** } \\
(0.484)\end{array}$ & $\begin{array}{l}1.115 \text { ** } \\
(0.334)\end{array}$ & $\begin{array}{l}2.252 \text { ** } \\
(0.565)\end{array}$ \\
\hline & Lead in 4 th quartile & $\begin{array}{l}1.133 \text { ** } \\
(0.386)\end{array}$ & $\begin{array}{l}1.223 \text { ** } \\
(0.370)\end{array}$ & $\begin{array}{l}1.300 \text { ** } \\
(0.443)\end{array}$ \\
\hline
\end{tabular}

Notes. Results shown are for the regression of log per capita violent crime on a spline of effective lead exposure. The cutpoints for the spline are at the quartiles of the effective lead measure. Coefficients shown are average elasticities of violent crime with respect to lead over the sample period and within each quartile. The regression includes all state-level controls and state and year fixed effects. The lead measures are described in the text and Data Appendix. Standard errors are shown in parentheses and are Huber-White robust and corrected for serial correlation in a short panel by clustering on state. Observations are weighted by state population. Significance is indicated by ** for $p$-values below 0.05 and * for $p$-values below 0.10 . 


\section{Appendix Table 4 . Murder Results Using Alternate Lead Measures and a Spline.}

\begin{tabular}{|c|c|c|c|c|c|}
\hline Specification & Sample & & $\begin{array}{c}\text { Grams Per } \\
\text { Gallon }\end{array}$ & $\begin{array}{c}\text { Per-Capita } \\
\text { Lead }\end{array}$ & $\begin{array}{l}\text { IV (gpg instr } \\
\text { for air) }\end{array}$ \\
\hline \multirow[t]{3}{*}{ Linear } & Full Sample & & $\begin{array}{l}0.369 \\
(0.596)\end{array}$ & $\begin{array}{r}-0.199 \\
(0.569)\end{array}$ & $\begin{array}{l}0.411 \\
(0.710)\end{array}$ \\
\hline & Drop NY & & $\begin{array}{l}0.684 \\
(0.561)\end{array}$ & $\begin{array}{l}0.524 \text { * } \\
(0.326)\end{array}$ & $\begin{array}{l}0.780 \\
(0.679)\end{array}$ \\
\hline & Drop 3 States & & $\begin{array}{l}1.075 \text { ** } \\
(0.393)\end{array}$ & $\begin{array}{l}0.699 * * \\
(0.232)\end{array}$ & $\begin{array}{l}1.281 \text { ** } \\
(0.469)\end{array}$ \\
\hline \multirow[t]{3}{*}{$\log$} & Full Sample & & $\begin{array}{r}-0.070 \\
(0.416)\end{array}$ & $\begin{array}{l}0.027 \\
(0.382)\end{array}$ & $\begin{array}{r}-0.003 \\
(0.579)\end{array}$ \\
\hline & Drop NY & & $\begin{array}{l}0.216 \\
(0.509)\end{array}$ & $\begin{array}{l}0.300 \\
(0.445)\end{array}$ & $\begin{array}{l}0.373 \\
(0.674)\end{array}$ \\
\hline & Drop 3 States & & $\begin{array}{l}0.310 \\
(0.402)\end{array}$ & $\begin{array}{l}0.428 \\
(0.318)\end{array}$ & $\begin{array}{l}0.604 \\
(0.512)\end{array}$ \\
\hline \multirow[t]{12}{*}{ Spline } & Full Sample & Lead in 1st quartile & $\begin{array}{r}-0.080 \\
(0.408)\end{array}$ & $\begin{array}{l}0.214 \\
(0.304)\end{array}$ & $\begin{array}{r}-0.139 \\
(0.560)\end{array}$ \\
\hline & & Lead in 2nd quartile & $\begin{array}{r}-0.220 \\
(0.579)\end{array}$ & $\begin{array}{r}-0.265 \\
(0.621)\end{array}$ & $\begin{array}{r}-0.243 \\
(0.710)\end{array}$ \\
\hline & & Lead in 3rd quartile & $\begin{array}{r}-0.135 \\
(1.040)\end{array}$ & $\begin{array}{r}-0.355 \\
(0.608)\end{array}$ & $\begin{array}{r}-0.119 \\
(1.231)\end{array}$ \\
\hline & & Lead in 4th quartile & $\begin{array}{l}1.883 \text { ** } \\
(0.814)\end{array}$ & $\begin{array}{l}0.573 \\
(0.516)\end{array}$ & $\begin{array}{l}1.902 \text { ** } \\
(0.984)\end{array}$ \\
\hline & Drop NY & Lead in 1st quartile & $\begin{array}{l}0.261 \\
(0.471)\end{array}$ & $\begin{array}{l}0.466 \\
(0.409)\end{array}$ & $\begin{array}{l}0.308 \\
(0.640)\end{array}$ \\
\hline & & Lead in 2nd quartile & $\begin{array}{l}0.032 \\
(0.599)\end{array}$ & $\begin{array}{l}0.763 \text { * } \\
(0.455)\end{array}$ & $\begin{array}{l}0.048 \\
(0.736)\end{array}$ \\
\hline & & Lead in 3rd quartile & $\begin{array}{l}0.620 \\
(0.838)\end{array}$ & $\begin{array}{l}0.139 \\
(0.514)\end{array}$ & $\begin{array}{l}0.783 \\
(0.965)\end{array}$ \\
\hline & & Lead in 4th quartile & $\begin{array}{l}2.137 \text { ** } \\
(0.744)\end{array}$ & $\begin{array}{l}1.097 \text { ** } \\
(0.497)\end{array}$ & $\begin{array}{l}2.156 \text { ** } \\
(0.914)\end{array}$ \\
\hline & Drop 3 States & Lead in 1st quartile & $\begin{array}{l}0.119 \\
(0.410)\end{array}$ & $\begin{array}{l}0.481 \text { * } \\
(0.277)\end{array}$ & $\begin{array}{l}0.158 \\
(0.544)\end{array}$ \\
\hline & & Lead in 2nd quartile & $\begin{array}{l}0.431 \\
(0.555)\end{array}$ & $\begin{array}{l}0.901 \text { ** } \\
(0.342)\end{array}$ & $\begin{array}{l}0.519 \\
(0.668)\end{array}$ \\
\hline & & Lead in 3rd quartile & $\begin{array}{l}1.221 \text { ** } \\
(0.507)\end{array}$ & $\begin{array}{l}0.315 \\
(0.379)\end{array}$ & $\begin{array}{l}1.420 \text { ** } \\
(0.589)\end{array}$ \\
\hline & & Lead in 4th quartile & $\begin{array}{l}2.046 \text { ** } \\
(0.631)\end{array}$ & $\begin{array}{l}1.201 \text { ** } \\
(0.323)\end{array}$ & $\begin{array}{l}2.346 \text { ** } \\
(0.723)\end{array}$ \\
\hline
\end{tabular}

Notes. Results shown are for the regression of log per capita murder on effective lead exposure. The baseline linear specification is identical to that shown in Column 9 of Table 6 . The regression includes all state-level controls and state and year fixed effects. For the spline, cutpoints are at the quartiles of the effective lead measure. The lead measures are described in the text and Data Appendix. Coefficients shown are average elasticities of murder with respect to lead over the sample period and within each quartile. Standard errors are shown in parentheses and are Huber-White robust and corrected for serial correlation in a short panel by clustering on state. Observations are weighted by state population. Significance is indicated by ** for $p$-values below 0.05 and * for $p$-values below 0.10 . 
Figure 1a.

Gasoline Lead Exposure 1960 to 1990.

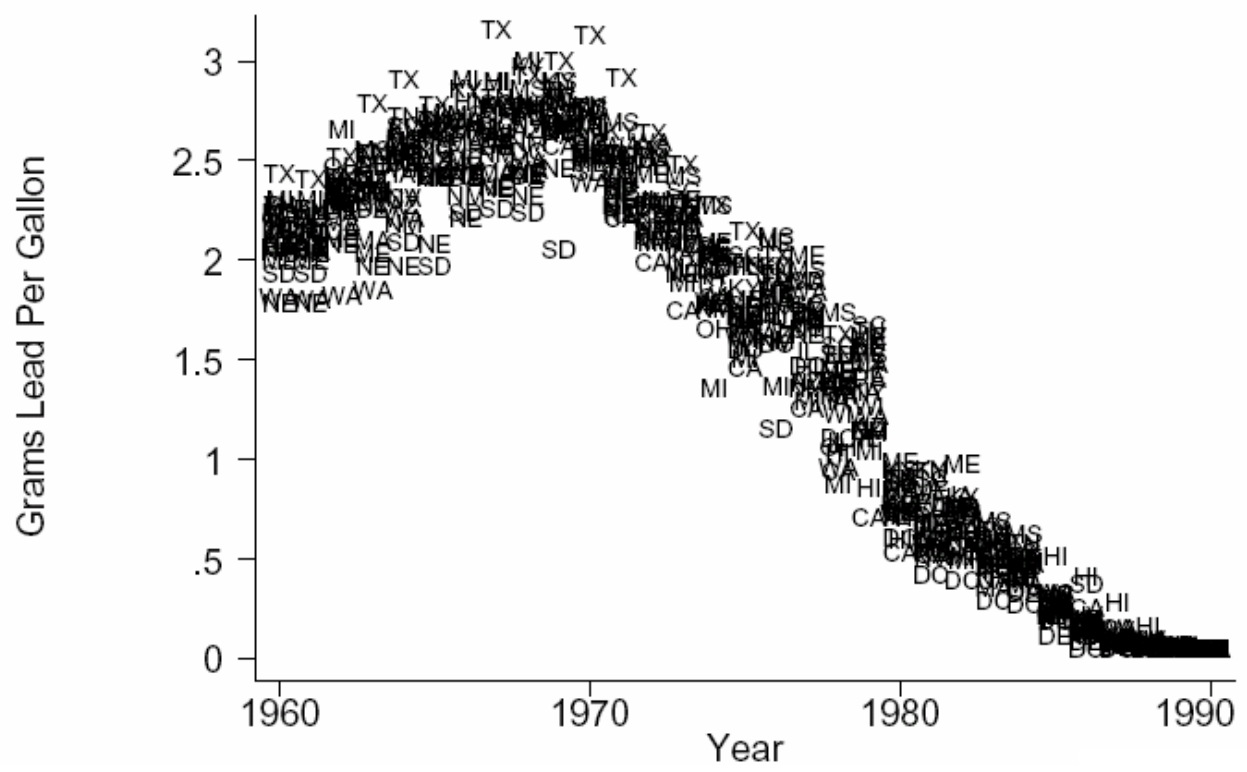

Figure $1 b$.

Air Lead Exposure 1960 to 1990.

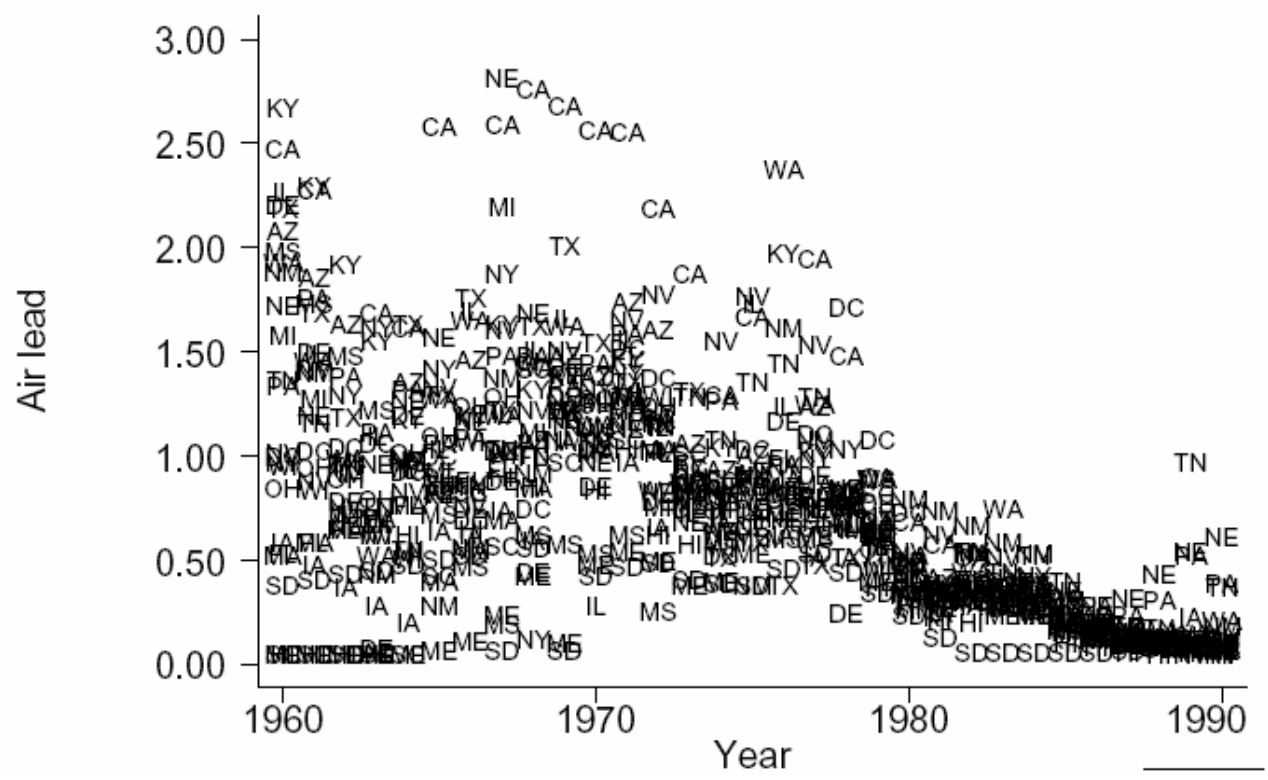

Source: Author's calculations as described in the text. Note: For readability, a random selection of 25 states is shown. 
Figure 2.

Lead in Paint and Gasoline 1900-1990.

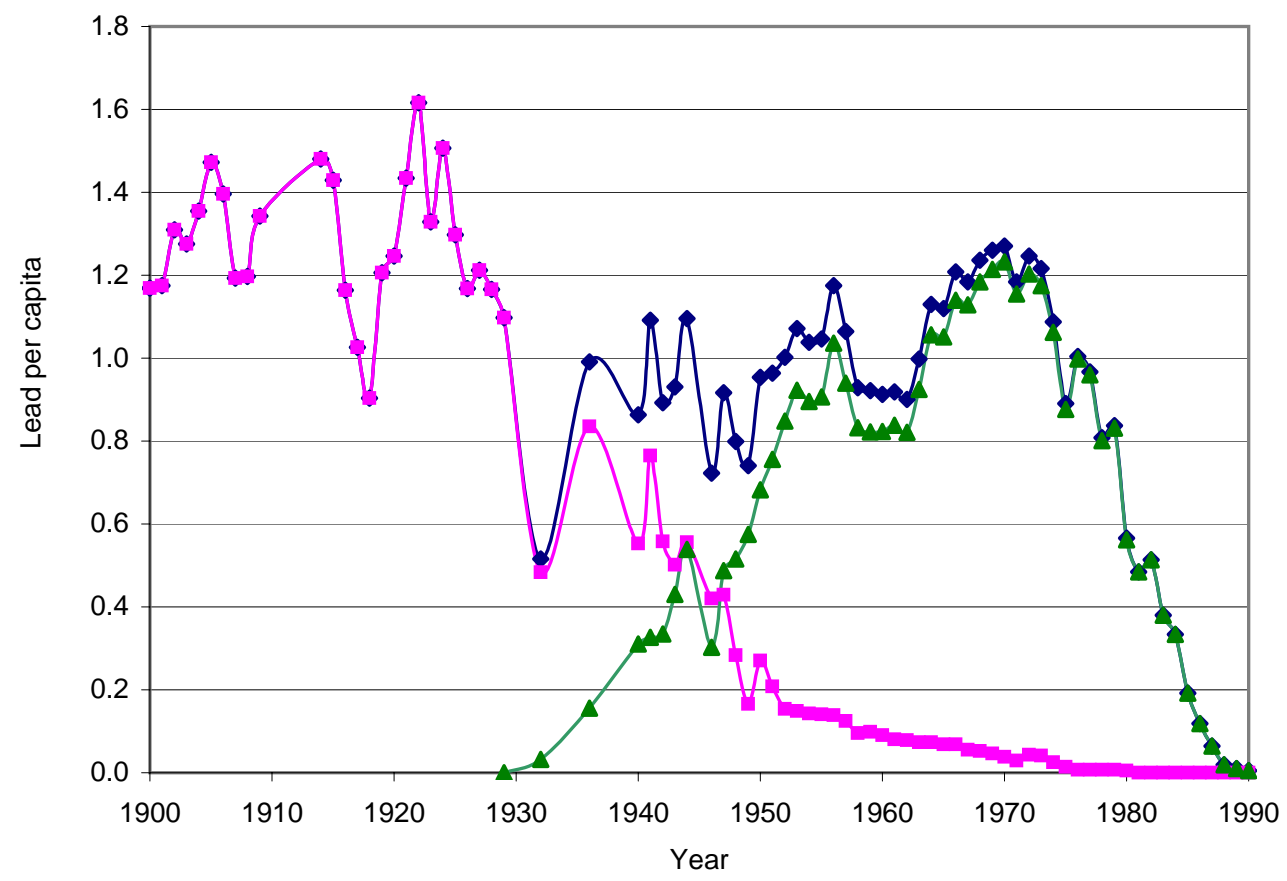

$$
\begin{aligned}
& \longrightarrow \text { Total Lead (ktons per capita) } \\
& \rightarrow-\text { Paint Lead (ktons per capita) } \\
& \neg \text { Gasoline Lead (ktons per capita) }
\end{aligned}
$$

Lead is presented as kilotons of lead per 1 million population. Sources: United States Geological Survey and U.S. Department of the Interior, 1904-1929, Mineral Resources of the United States. United States Geological Survey and U.S. Department of the Interior, 19331980, Minerals Yearbook. United States Geological Survey and U.S. Department of the Interior, 2001, U.S. Consumption of Lead in Manufacture of Gasoline Additives, 1941-1986. Statistical Abstract of the United States, 2002. Gasoline data prior to 1940 is approximate. 
Figure 3.

Crime Rates 1970-2002.

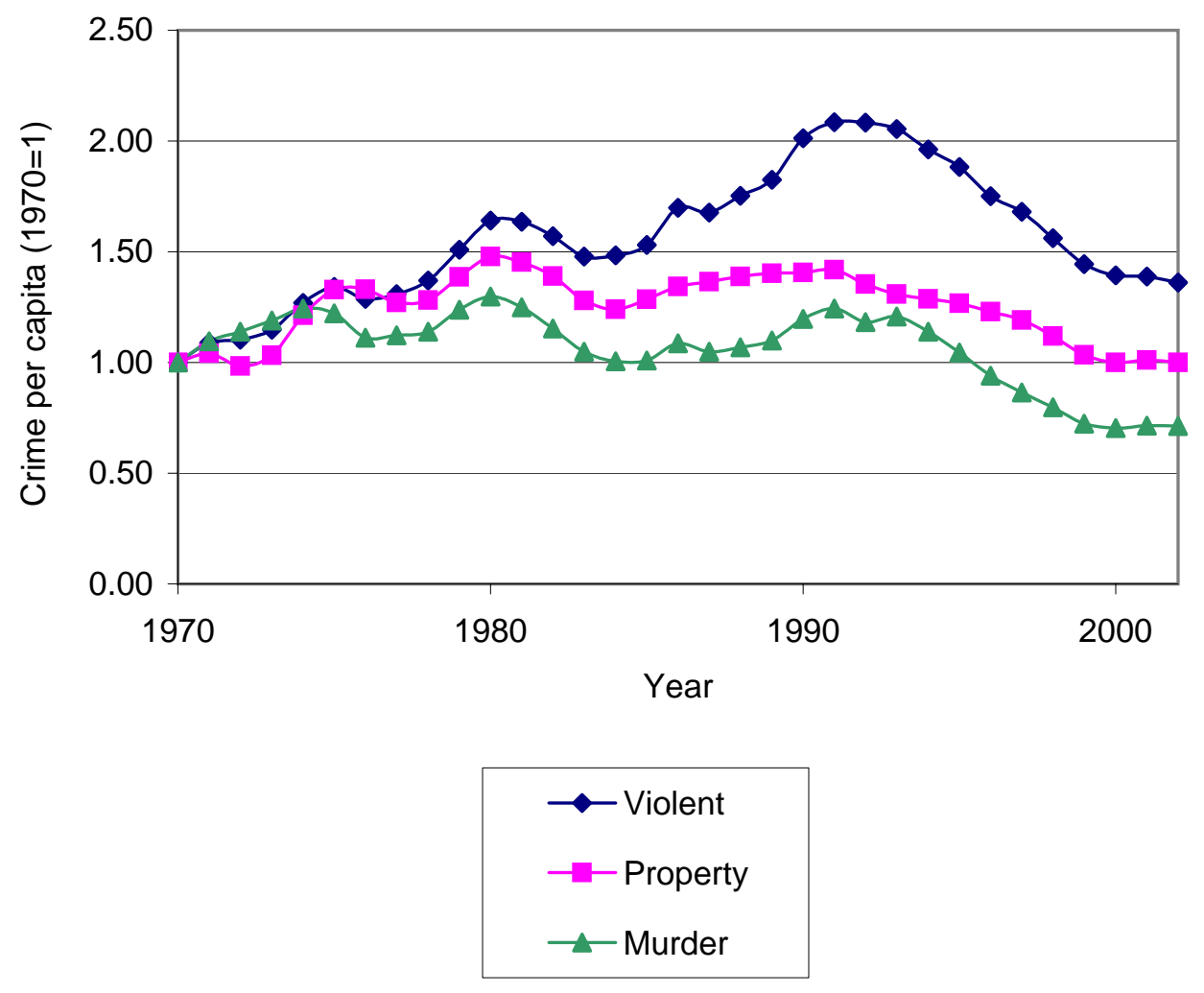

Source: Federal Bureau of Investigation, Uniform Crime Reports for the United States, annual, Washington, D.C.: U.S. Government Printing Office. 
Figure 4.

Violent Crime and Lead (22-year lag).

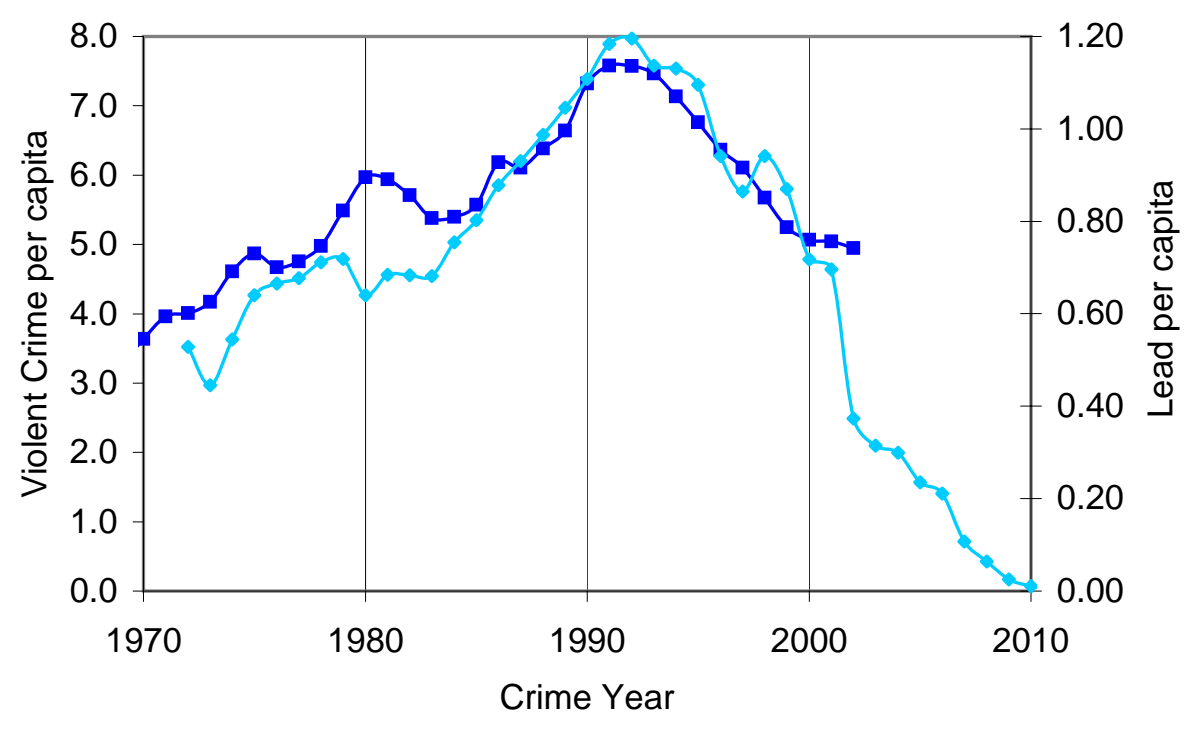

$\rightarrow-$ Violent Crime (per 1000 pop)
$\rightarrow-$ Lead (kg per 1000 pop)

Sources: Federal Bureau of Investigation, Uniform Crime Reports for the United States, annual, Washington, D.C.: U.S. Government Printing Office. U.S. Consumption of Lead in Manufacture of Gasoline Additives, 1941-1986. 
Figure 5.

Violent Crime 1960 to 1990, High Lead and Low Lead States

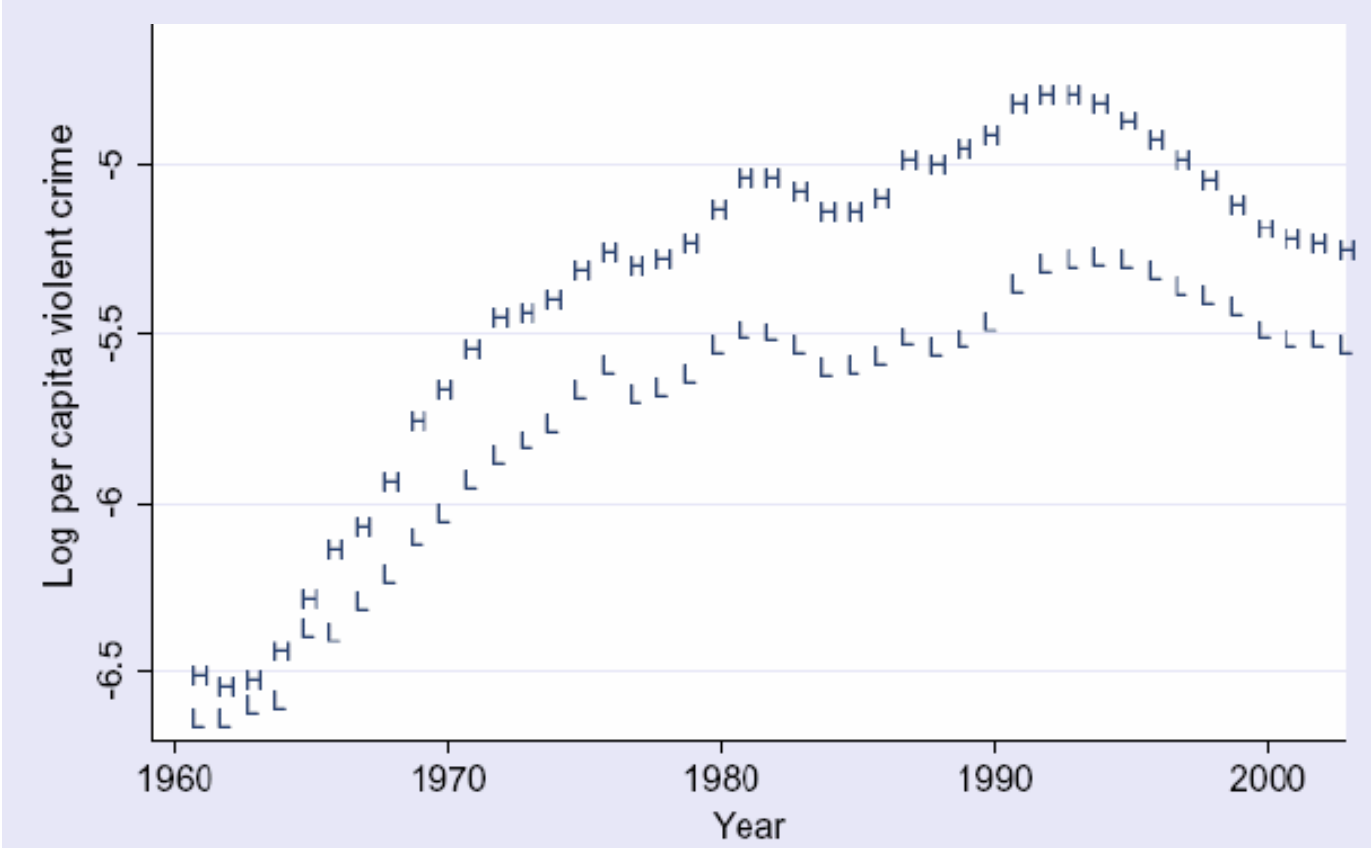

Source: Author's calculations as described in the text. 